\title{
One-Pot Synthesis and Structural Evolution of Colloidal Cesium Lead Halide-Lead Sulfide Heterostructure Nanocrystals for Optoelectronic Applications
}

Metikoti Jagadeeswararao $^{\S}$, II, Parth Vashishtha ${ }^{\ddagger}$, Thomas J.N. Hooper ${ }^{\ddagger}$, Anil Kanwat ${ }^{\S}$, Jia Wei Melvin Lim ${ }^{\mathbb{P}}$, \#, Sujaya Kumar Vishwanath ${ }^{\dagger}$, Natalia Yantara ${ }^{\S}$, Taewook Park ${ }^{\mathbb{I}}$, Tze Chien Sum $\mathbb{P}^{\mathbb{P}}$, Dae Sung Chung ${ }^{\mathbb{I l}}$, Subodh G. Mhaisalkar ${ }^{\S}$, and Nripan Mathews ${ }^{\dagger}, \S *$

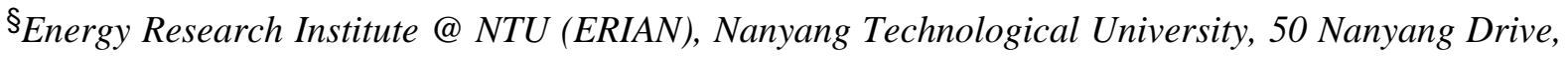
Singapore 637553, Singapore

† School of Materials Science and Engineering, Nanyang Technological University (NTU), 50 Nanyang Avenue, Singapore 639798, Republic of Singapore

\$ Center of High Field NMR Spectroscopy and Imaging, Nanyang Technological University, 21 Nanyang Link, Singapore 637371

PDivision of Physics and Applied Physics, School of Physical and Mathematical Sciences, Nanyang Technological University, Singapore 637371, Singapore

\#Energy Research Institute @NTU (ERI@N), Interdisciplinary Graduate Programme, Nanyang Technological University, Singapore 637371, Singapore

II Department of Chemical Engineering, Pohang University of Science and Technology (POSTECH), Pohang 37363, Republic of Korea

Corresponding Author: E-mail: Nripan@ntu.edu.sg 


\section{Chemicals}

Lead bromide (99.5\%), lead iodide (99.999\%), lead chloride (99.999\%), cesium carbonate (99.9\%), thioacetamide ( $\geq 99.0 \%)$, 1-octadecene $(90 \%)$, oleylamine $(70 \%)$, trioctylphosphine (97\%), oleic acid (90\%), methyl acetate (anhydrous, 99.5\%), hexane (anhydrous, 95\%) were purchased from Sigma-Aldrich and used as such unless until mentioned further purification.

\section{Experimental section}

\section{Cs-oleate preparation}

$134.4 \mathrm{mg}$ of cesium carbonate was loaded in a 3-neck round bottom flask along with $5 \mathrm{~mL} 1$ octadecene and $1 \mathrm{~mL}$ oleic acid, degassed for 1 hour at $100{ }^{\circ} \mathrm{C}$ followed by shifted to nitrogen $\left(\mathrm{N}_{2}\right)$ environment then the temperature was raised to $150{ }^{\circ} \mathrm{C}$ to make sure cesium carbonate get dissolved completely. After that natural cooling to room temperature (RT).

\section{Synthesis of $\mathrm{CsPbX}_{3}-\mathrm{PbS}$ heterostructure nanocrystals (HNCs)}

To synthesize CsPbBr3-PbS HNCs, $0.19 \mathrm{mmol}$ ( $70 \mathrm{mg}$ ) of lead bromide was loaded in a 3neck round bottom flask containing $5 \mathrm{~mL}$ 1-octadecene and this mixture was degassed for 1 hour at $100{ }^{\circ} \mathrm{C}$. After which, the reaction flask was switched to the $\mathrm{N}_{2}$ environment followed by the injection of $0.30 \mathrm{~mL}$ of dried oleylamine (OLA) and $0.55 \mathrm{~mL}$ dried oleic acid. This reaction mixture was degassed for another 15 minutes at $100{ }^{\circ} \mathrm{C}$ under vacuum and then finally switched back to the $\mathrm{N}_{2}$ environment. The temperature of the lead bromide solution was then raised to $135{ }^{\circ} \mathrm{C}$ for dropwise addition of thioacetamide solution containing $5 \%$ (4 mg) of thioacetamide dissolved in $0.25 \mathrm{~mL}$ of dried OLA. This addition results in a color change of reaction mixture from colorless to a dark brown color solution. Subsequently, the temperature of the solution was further raised to $160{ }^{\circ} \mathrm{C}$, then $0.5 \mathrm{~mL}$ Cs-oleate (which was heated up to 80-100 ${ }^{\circ} \mathrm{C}$ before injection) was injected swiftly, after 5-8 sec, the reaction flask was cooled down in an ice-water bath. After Cs-oleate injection the color of the solution turns black greenish as shown in Figure S1a. The reaction mixture was kept at RT for 15 minutes then the solution was centrifuged for $8000 \mathrm{rpm}$ for 5 minutes and collected the decant was dispersed in $1 \mathrm{~mL}$ anhydrous hexane. To this, $1 \mathrm{~mL}$ methyl acetate (MeOAc) was added and again the mixture was centrifuged for $5 \mathrm{~min}$ at $8000 \mathrm{rpm}$, the resulting precipitate was collected. The final precipitate was then dispersed in $1 \mathrm{~mL}$ hexane for further characterization. To make $2 \%$, $1.2 \mathrm{mg}$ of thioacetamide was dissolved in $0.25 \mathrm{~mL}$ dried OLA. The remaining procedure was the same as $5 \%$ reaction. To synthesize $\mathrm{CsPbI}_{3}-\mathrm{PbS}$ and $\mathrm{CsPCl}_{3}-\mathrm{PbS} \mathrm{HNCs} 0.19 \mathrm{mmol}$ of 
$\mathrm{PbI}_{2}$ and $\mathrm{PbCl}_{2}$ were used. Additionally, $1 \mathrm{~mL}$ trioctylphosphine (TOP) was added to $\mathrm{PbCl}_{2}$ solution. The remaining procedure is similar to the synthesis of $\mathrm{CsPbBr} 3-\mathrm{PbS} \mathrm{HNCs}$.

\section{Large scale synthesis of $\mathrm{CsPbBr}_{3}-\mathrm{PbS}$ and $\mathrm{CsPbI}_{3}-\mathrm{PbS}$ HNCs:}

$2.1 \mathrm{mmol}$ of $\mathrm{PbBr}_{2}$ has been taken in a $500 \mathrm{~mL}$ round bottom flask which contains $50 \mathrm{~mL} \mathrm{1-}$ octadecene. This mixture was degassed for 30 minutes to one hour at $100{ }^{\circ} \mathrm{C}$ followed by the injection of $5 \mathrm{~mL} \mathrm{OA}$ and $4 \mathrm{~mL}$ OLA under $\mathrm{N}_{2}$ environment. Again, the above reaction mixture was degassed at $100{ }^{\circ} \mathrm{C}$ and $110^{\circ} \mathrm{C}$ for 30 minutes. After degassing $1 \mathrm{~mL}$ of the sulfur precursor was injected dropwise at $135{ }^{\circ} \mathrm{C}$ under $\mathrm{N}_{2}$ environment. A sulfur precursor was prepared by dissolving $\sim 0.5 \mathrm{mmol}$ thioacetamide in $1 \mathrm{~mL}$ OLA by sonication. After that, the reaction temperature has been raised to $160{ }^{\circ} \mathrm{C}$. At this temperature, $4 \mathrm{~mL}$ of Cs-oleate (which was heated to $80{ }^{\circ} \mathrm{C}$ before injection) was swiftly injected, after $5-8 \mathrm{sec}$, the reaction flask was cooled down in an ice-water bath until the solution becomes completely freezes. This NC solution allowed to reach RT. Then, this solution has been divided into eight parts in $50 \mathrm{ml}$ centrifugation tubes. To each tube, $24 \mathrm{~mL}$ of MeOAc was added followed by centrifugation at $8000 \mathrm{rpm}$ for 5 minutes. The resultant wet pellet was dispersed in $3 \mathrm{~mL}$ of hexane. To this 6 $\mathrm{mL}$ of MeOAc was added followed by centrifugation at $10000 \mathrm{rpm}$ for 5 minutes. The final wet pellet was dispersed in $10 \mathrm{~mL}$ hexane. Larger size NCs have been removed by the centrifugation at $4000 \mathrm{rpm}$ for $5 \mathrm{~min}^{1}$

\section{Synthesis of $\mathrm{CsPbX}_{3} \mathrm{NCs}$}

Synthesis of $\mathrm{CsPbBr}_{3} \mathrm{NCs}$ is similar to $\mathrm{CsPbBr}_{3}-\mathrm{PbS}$ HNCs, since the sulfur source is not needed in this case, $0.55 \mathrm{~mL}$ dried OLA was added to lead bromide solution along with 0.55 mL OA. The remaining the procedure is same for both $\mathrm{CsPbBr}_{3} \mathrm{NCs}$ and $\mathrm{CsPbBr}_{3}-\mathrm{PbS}$ HNCs. To synthesize $\mathrm{CsPbI}_{3}$ and $\mathrm{CsPbCl}_{3} \mathrm{NCs} \mathrm{PbI}_{2}$ and $\mathrm{PbCl}_{2}$ were used respectively. Additionally, $1 \mathrm{~mL}$ TOP was used to dissolve $\mathrm{PbCl}_{2}$. The remaining procedure is similar to the synthesis of $\mathrm{CsPbBr}_{3} \mathrm{NCs}$.

\section{Synthesis of $\mathrm{PbS}$ NCs from $\mathrm{PbBr}_{2}, \mathrm{PbI}_{2}$, and $\mathrm{PbCl}_{2}$ sources}

To synthesize $\mathrm{PbS} \mathrm{NCs}$ from $\mathrm{PbBr}_{2}, \mathrm{PbI}_{2}$, and $\mathrm{PbCl}_{2}$ sources $5 \%$ of thioacetamide was added to $\mathrm{PbBr}_{2}, \mathrm{PbI}_{2}$, and $\mathrm{PbCl}_{2}$ solution as described in the synthesis of $\mathrm{CsPbBr}_{3}-\mathrm{PbS}, \mathrm{CsPb}_{3}-\mathrm{PbS}$, and $\mathrm{CsPCl}_{3}-\mathrm{PbS} \mathrm{HNCs}$ respectively, for about one minute followed by sudden cooling by an ice water bath. PbS NCs were purified by excess MeOAc solvent and centrifuged at $8000 \mathrm{rpm}$ for 5 minutes to collect the precipitate. The obtained precipitate was dispersed in $1 \mathrm{~mL}$ hexane solvent. These $\mathrm{PbS}$ NCs were washed one more time with a 1:1 ratio of MeOAc. The final 
precipitate was dispersed in hexane for further characterization. In the manuscript, the $\mathrm{PbS}$ NCS from different halide sources have been represented by PbS NCs@PbBr2, PbS NCs@ $\mathrm{PbCl}_{2}$, and PbS NCs@PbI2.

\section{Characterization}

UV-visible-NIR absorption and PL spectra were collected using Shimatzu and Horiba instruments, respectively. A small amount of NCs was dispersed in a quartz cuvette containing $\sim 3 \mathrm{~mL}$ hexane for UV and PL measurements. XRD measurement of $\mathrm{CsPBr}_{3}-\mathrm{PbS}$ HNCs, $\mathrm{PbS}$ $\mathrm{NCs} @ \mathrm{PbBr}_{2}$ and $\mathrm{CsPbBr}_{3} \mathrm{NCs}$ were conducted using a PANalytical X-ray diffractometer equipped with a $1.8 \mathrm{~kW} \mathrm{Cu} \mathrm{Ka} \mathrm{X-ray} \mathrm{tube} \mathrm{and} \mathrm{operating} \mathrm{at} 45 \mathrm{kV}$ and $30 \mathrm{~mA}$. The diffraction patterns were collected in the air at room temperature using Bragg-Brentano geometry. $\mathrm{CsPbCl}_{3} \mathrm{NCs}, \mathrm{CsPbI}_{3} \mathrm{NCs}$ and $\mathrm{CsPbCl}_{3}-\mathrm{PbS}, \mathrm{CsPbI}_{3}-\mathrm{PbS}$ HNCs XRD were collected using

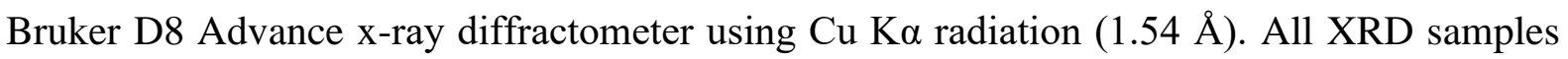
were prepared by drop-casting a concentrated solution on a zero-diffraction silicon holder unless until mentioned. For Ultraviolet photoelectron spectroscopy (UPS) measurements for $\mathrm{CsPbBr}_{3}-\mathrm{PbS} \mathrm{HNCs}$, $\mathrm{PbS}$ NCs from $\mathrm{PbBr}_{2}$ source and $\mathrm{CsPbBr}_{3}$ NCs solution was drop cast on ITO substrates. Whereas, samples correspond to $\mathrm{PbS}$ NCs @ $\mathrm{PbI}_{2}, \mathrm{CsPbI}_{3} \mathrm{NCs}$ and $\mathrm{CsPbI}_{3}-$ $\mathrm{PbS}$ were done on silicon wafer. High-resolution transmission electron microscopy (HRTEM) measurements of $\mathrm{CsPbBr}_{3} \mathrm{NCs}$ and $\mathrm{CsPbBr}_{3}-\mathrm{PbS}$ HNCs were performed by Jeol 2100F. The measurements were carried out with a beam current of $146 \mu \mathrm{A}$ and an accelerating voltage of $200 \mathrm{kV}$. TEM measurements of $\mathrm{CsPbCl}_{3} \mathrm{NCs}, \mathrm{CsPbI}_{3} \mathrm{NCs}$ and $\mathrm{CsPbCl}_{3}-\mathrm{PbS}, \mathrm{CsPbI}_{3}-\mathrm{PbS}$ HNCs were measured using JEM-ARM. Samples were prepared by drop-casting diluted NCs solution (in hexane) onto the $\mathrm{Cu}$ grid. Fourier Transform Infrared Spectroscopy (FTIR) analyses were carried out using VERTEX 70v FT-IR spectrometer for the colloidal dispersion in hexane solvent. S-4800 from Hitachi Scanning electron microscope (SEM) have utilized for the measurement of energy dispersive spectroscopy (EDS) analysis for $\mathrm{CsPbCl}_{3}-\mathrm{PbS}, \mathrm{CsPbI}_{3}-$ PbS HNCs.

\section{Time-resolved photoluminescence measurement}

Time-resolved photoluminescence (TRPL) measurements were performed using a home-built setup. The excitation laser is a Coherent LIBRA, with a pulse duration of $\sim 50 \mathrm{fs}$ and a repetition rate of $1 \mathrm{kHz}$. The $400 \mathrm{~nm}$ pump beam was generated from frequency doubling the $800 \mathrm{~nm}$ fundamental beam using a BBO crystal. The residual $800 \mathrm{~nm}$ beam was filtered out with appropriate filters after frequency doubling. The photoluminescence was collected with 
a lens pair and directed into a monochromator (Princeton Instrument SP2300i) which was coupled to the streak camera (Optronis Optoscope) for measurement. The pump fluence used for the TRPL measurements was $4.5 \mu \mathrm{Jcm}^{-2}$.

\section{Photoluminescence quantum yield (PL QY) measurements}

PL QY measurements have been carried out by exciting the samples with a $445 \mathrm{~nm}$ continuouswave diode laser (Cobolt) in an integrating sphere (Labsphere). The output of the integrating sphere is coupled through an optical fiber to a charge-coupled device (Newton $920 \mathrm{CCD}$, Andor) in which the photon count is captured. Samples were prepared by taking the dilute solutions of nanocrystals in hexane solvent with absorbance $\sim 0.2$.

\section{UPS measurements:}

X-ray photoelectron spectroscopy (XPS) depth profiling was performed using an AXIS Supra spectrometer (Kratos Analytical Inc., UK) equipped with a hemispherical analyzer and a monochromatic Al K-alpha source $(1487 \mathrm{eV})$ operated at $15 \mathrm{~mA}$ and $15 \mathrm{kV}$. The etching was done with an Ar Gas Cluster Ion Source (GCIS, Kratos Analytical Inc., Minibeam 6) operated at $10 \mathrm{keV}$, Ar1000+ with a roster size of $2 \times 2 \mathrm{~mm} 2$. The high-resolution XPS spectra were acquired from an area of $700 \times 300 \mu \mathrm{m} 2$ after 60 -s etch for each cycle. The sample was electrically grounded to the sample holder to prevent charge build-up on the sample surface. This instrument has used for $\mathrm{CsPbBr}_{3} \mathrm{NCs}$ and $\mathrm{CsPbBr}_{3}-\mathrm{PbS}$ HNCs. UPS measurements of $\mathrm{CsPbCl}_{3} \mathrm{NCs}, \mathrm{CsPbI}_{3} \mathrm{NCs}$, and $\mathrm{CsPbCl}_{3}-\mathrm{PbS}, \mathrm{CsPb}_{3}-\mathrm{PbS} \mathrm{HNCs}$ were measured in an ultrahigh-vacuum chamber with a 4D beamline equipped with an electron analyzer and heating element, at the Pohang Acceleration Laboratory. Results were corrected for charging effects using an Au internal reference.

\section{Solid-state NMR measurements}

All-solid-state NMR experiments in this study were completed on a 14.1 T Bruker Advance III HD $600 \mathrm{MHz}$ spectrometer with a Bruker 1.9mm HXY MAS probe operating at a MAS frequency of $24 \mathrm{kHz}$. The ${ }^{133} \mathrm{Cs} \mathrm{NMR}\left(\nu_{0}\left({ }^{133} \mathrm{Cs}\right)=78.729 \mathrm{MHz}\right)$ experiments employed a onepulse sequence, utilizing a selective $\pi / 2$ pulse of $6.5 \mu$ s (determined on $\mathrm{CsCl}_{(\mathrm{s})}$ ) and a recycle delay of 30-200 s. The resulting data was referenced with respect to $0.1 \mathrm{M} \mathrm{CsNO}_{3(\mathrm{aq})}\left(\delta_{\text {iso }}=0\right.$ ppm). The ${ }^{207} \mathrm{~Pb}$ NMR $\left(20\left({ }^{207} \mathrm{~Pb}\right)=125.745-125.595 \mathrm{MHz}\right)$ experiments employed a Hahnecho pulse sequence, utilizing $\pi / 2$ and $\pi$ pulses of 4.125 and $8.25 \mu$ s (determined on $1.1 \mathrm{M}$ $\left.\mathrm{Pb}\left(\mathrm{NO}_{3}\right)_{2(\mathrm{aq})}\right)$, a recycle delay of 1-2 s, and a rotor synchronized echo delay of $35.5 \mu \mathrm{s}$. The

${ }^{207} \mathrm{~Pb}$ experiments utilized variable offset cumulative spectroscopy (VOCs) frequency stepping 
where appropriate to allow for full excitation of the broader NMR line-shapes present in some of the spectra. The resulting data were referenced with respect to $1.1 \mathrm{M} \mathrm{Pb}\left(\mathrm{NO}_{3}\right)_{2 \text { (aq) }}\left(\delta_{\text {iso }}=\right.$ $-2965.7 \mathrm{ppm})$. All spectral simulation was performed using the DMFit software package. ${ }^{2}$

\section{Stability checking of $\mathrm{CsPbBr}_{3}-\mathrm{PbS}$ HNCs:}

Typically, $\mathrm{CsPbBr} 3 \mathrm{NCs}$ having cubic and orthorhombic phases show high photoluminescence quantum yield (PLQY) unlike the orthorhombic phase of $\mathrm{CsPbI}_{3}$ NCs. Therefore, phase stability is not studied for $\mathrm{CsPbBr}_{3}-\mathrm{PbS} \mathrm{HNCs}$ rather polar solvent treatment, ambient stability, and UV light exposure was studied for $\mathrm{CsPbBr}_{3}-\mathrm{PbS}$ HNCs and $\mathrm{CsPbBr} 3$ NCs. Fig. S19 shows the PL intensity change of ethanol treatment for 2 hours. Interestingly, $\mathrm{CsPbBr} 3-\mathrm{PbS} \mathrm{HNCs}$ exhibits better stability compared with $\mathrm{CsPbBr}_{3} \mathrm{NCs}$. On the other hand, films of $\mathrm{CsPbBr}_{3} \mathrm{NCs}$ and $\mathrm{CsPbBr}_{3}-\mathrm{PbS}$ HNCs show similar stability towards ambient and UV light exposure (Fig. S20 and S21). Therefore, with a broad absorption range from $400 \mathrm{~nm}$ to $750 \mathrm{~nm}$ with type I band alignment, less trap state density, and better stability, $\mathrm{CsPbBr} 3-\mathrm{PbS} \mathrm{HNCs}$ can be a potential candidate for photocatalysis, photomultiplication, and other optoelectronic applications.

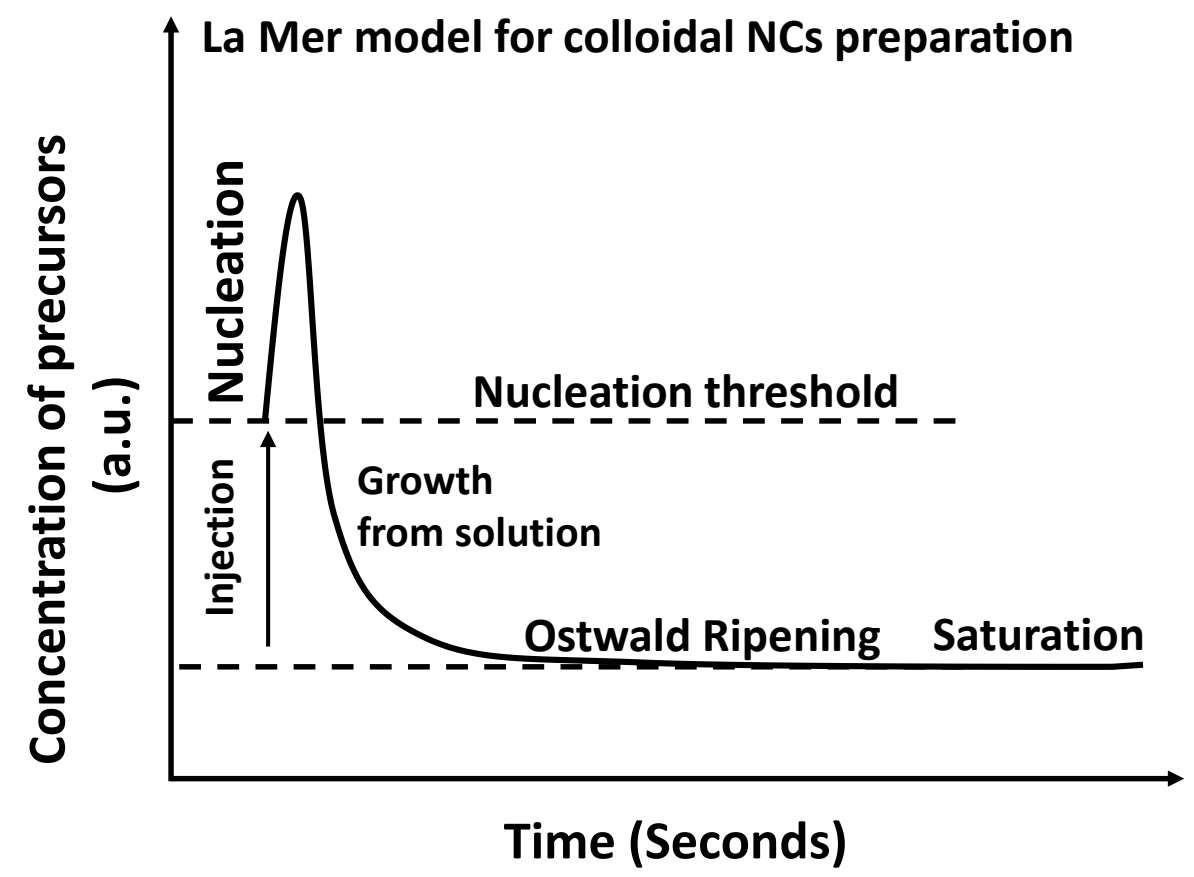

Figure S1. La Mer model for preparing monodisperse colloidal nanocrystals. ${ }^{3}$ 


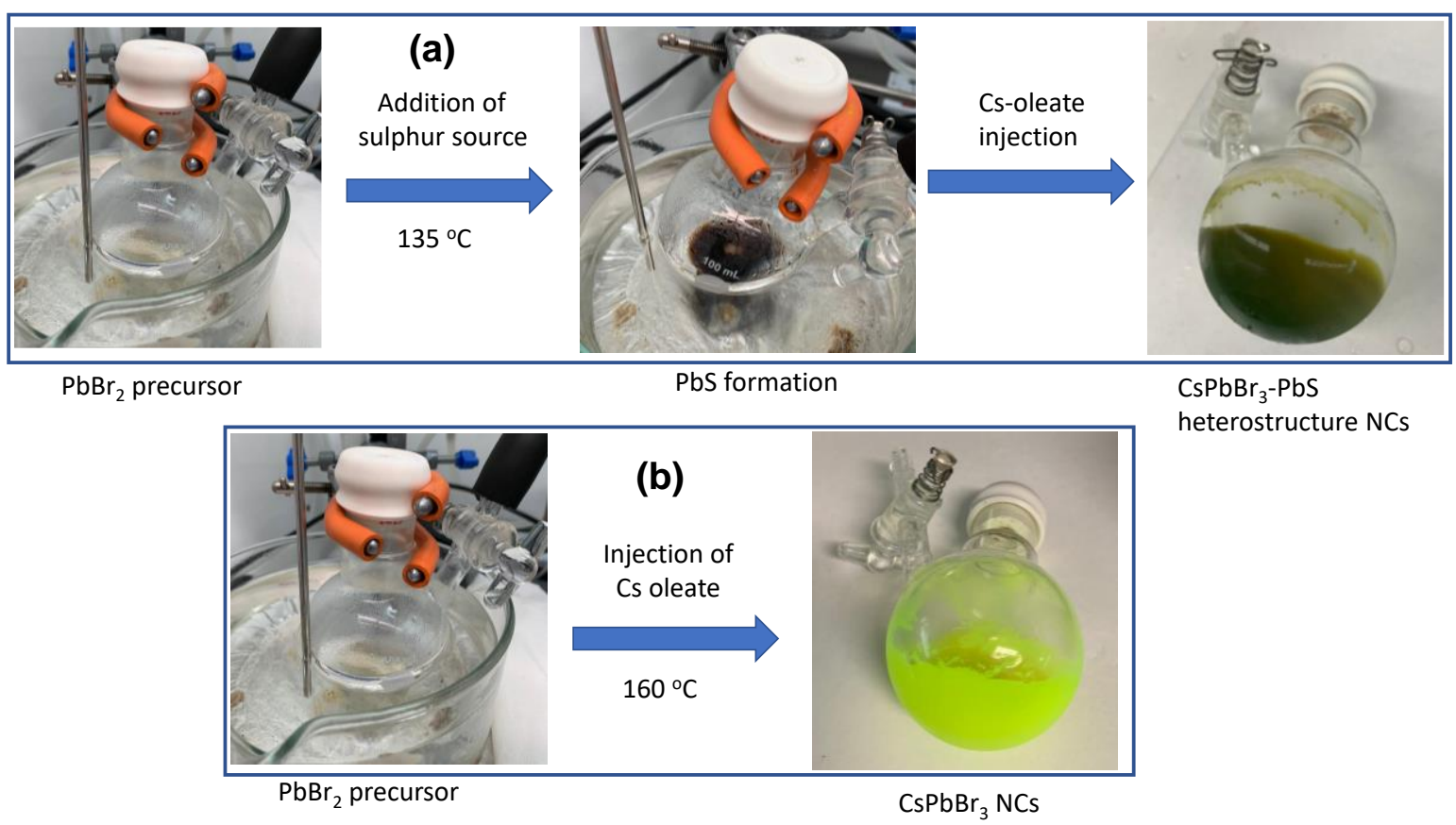

Figure S2. a) and b) are the photographs of the formation of $\mathrm{Cs} \mathrm{PbBr}_{3}-\mathrm{PbS}$ heterostructure nanocrystals (HNCs) and $\mathrm{CsPbB} 3$ nanocrystals (NCs).

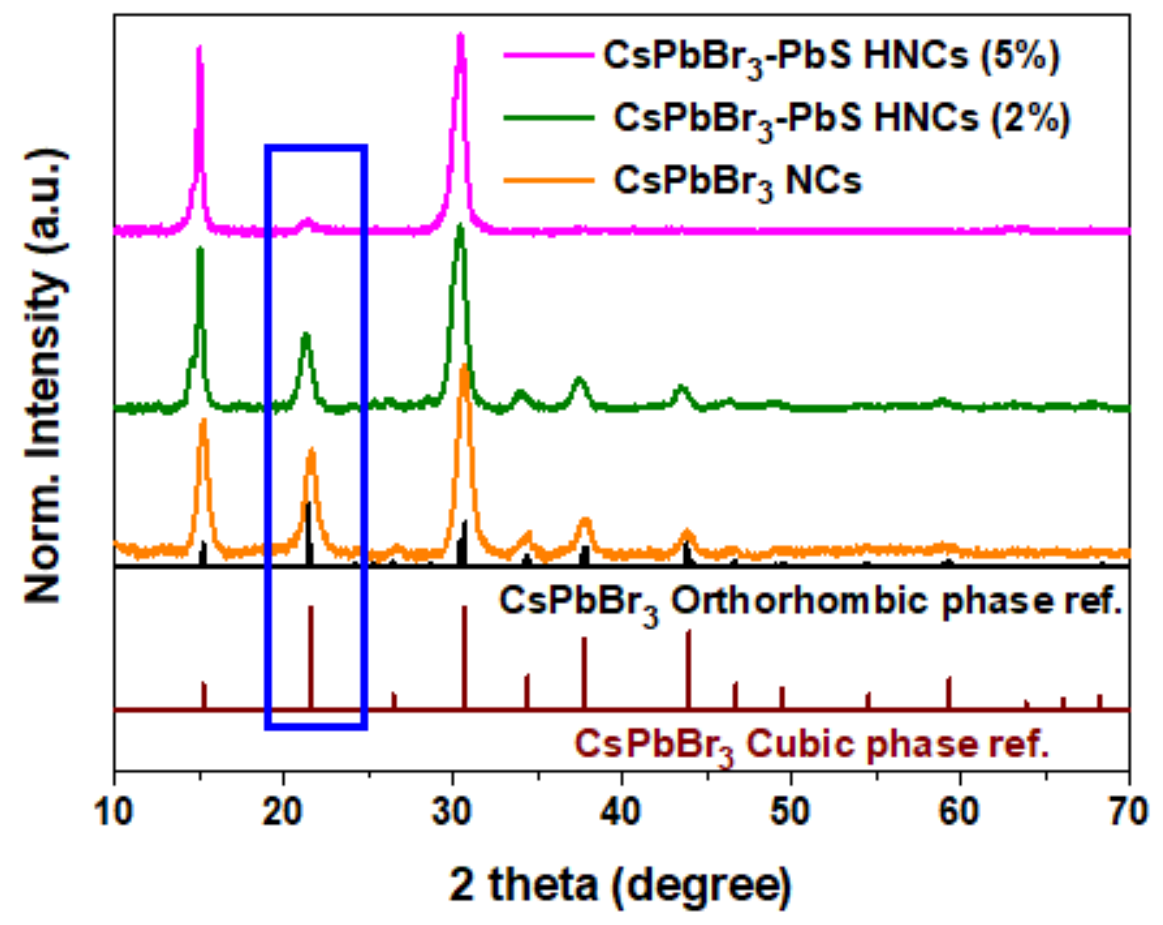

Figure S3. Powder x-ray diffraction (XRD) patterns of $\mathrm{CsPbBr} 3-\mathrm{PbS} \mathrm{HNCs}$ with $2 \%$ and $5 \%$ along with reference orthorhombic and cubic patterns. The intensity of the peak at $21.5^{\circ}$ is gradually decreased from $2 \%$ to $5 \%$ suggesting the growth of $\mathrm{CsPbBr} 3$ perovskite along with peaks at $\sim 15.2^{\circ}$ and $30.7^{\circ}$ according to HRTEM analysis. We note that with the broadening of $\mathrm{XRD}$ peaks for smaller size $\mathrm{CsPbBr}_{3}-\mathrm{PbS} \mathrm{HNCs}$ it is difficult to distinguish between orthorhombic and cubic phases both exhibiting similar Bragg`s angles for intense peaks. 

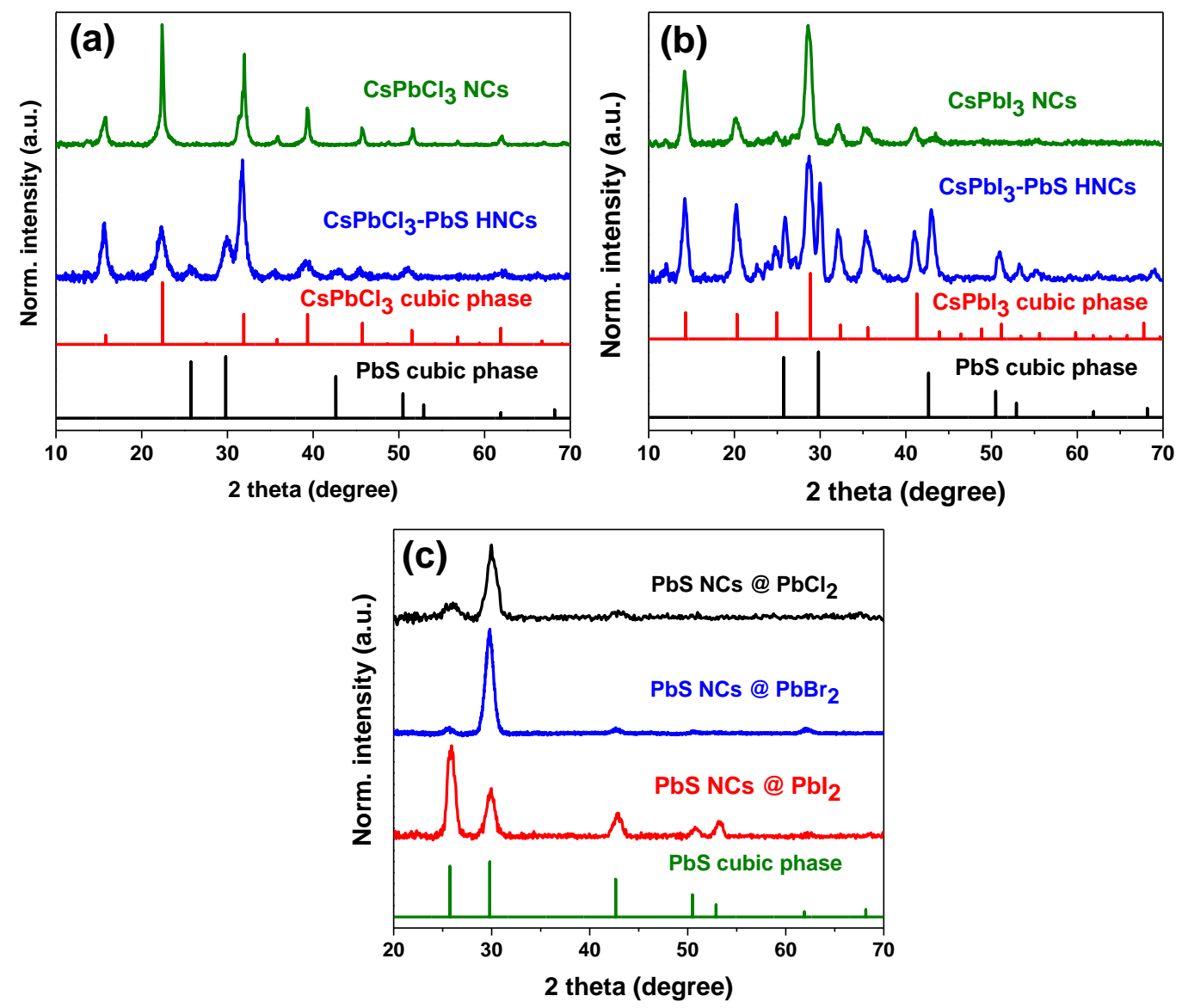

Figure S4. a) XRD plot of $\mathrm{CsPbCl}_{3} \mathrm{NCs}$ and $\mathrm{CsPbCl}_{3}-\mathrm{PbS}$ HNCs, b) XRD plot of $\mathrm{CsPbI}_{3} \mathrm{NCs}$ and $\mathrm{CsPbI}_{3}-\mathrm{PbS} \mathrm{HNCs}$, and c) $\mathrm{XRD}$ plot of $\mathrm{PbS}$ NCs formed from upon thioacetamide and various lead sources i.e. lead chloride, lead bromide, and lead iodide, respectively.
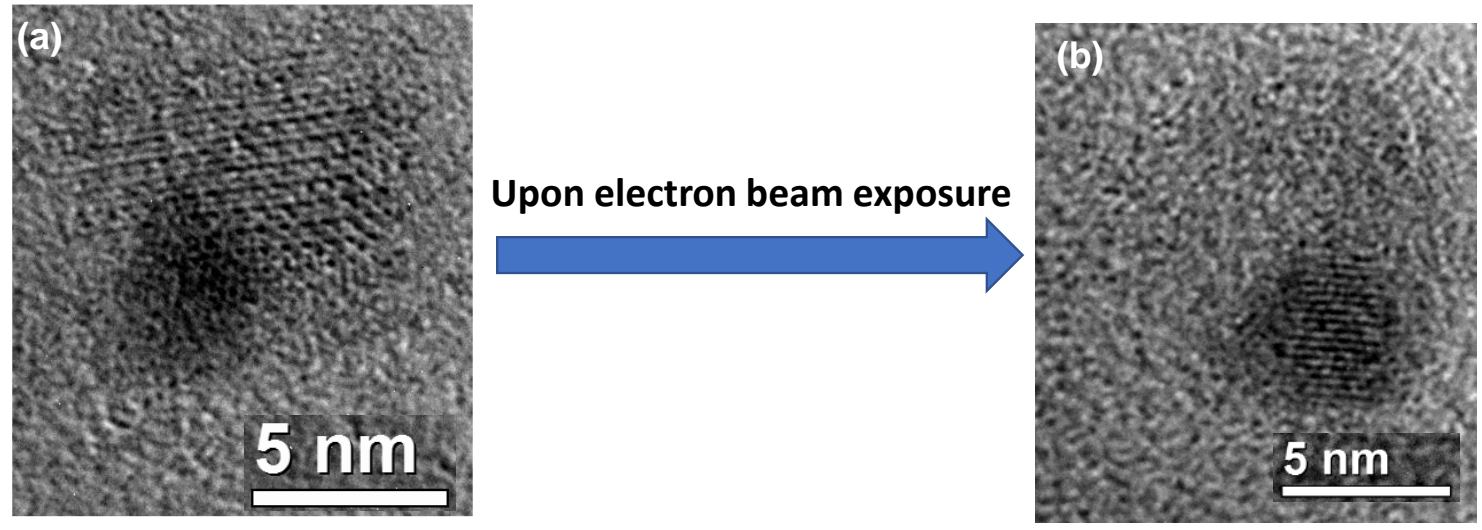

Figure S5. a) and b) are TEM images of $\mathrm{CsPbBr}_{3}-\mathrm{PbS}$ HNCs. Upon electron beam exposure under high-resolution imaging conditions, from a) to b) the damage of $\mathrm{CsPbBr}_{3}$ perovskite which is attached to $\mathrm{PbS}$ particle can be observed. On the other hand, damage of perovskite is very less under low resolution. 

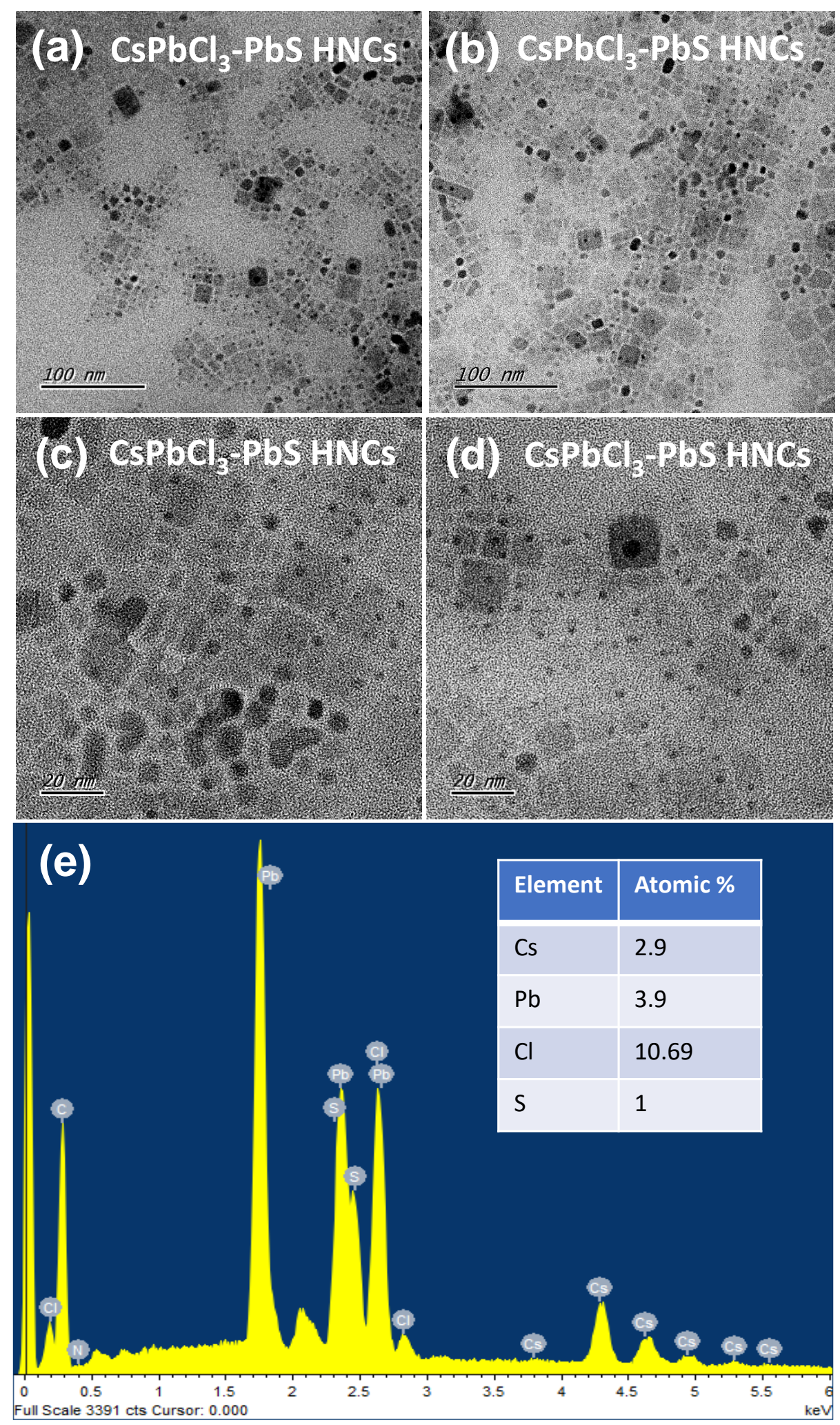

Figure S6. a,b,c,d) TEM images of $\mathrm{CsPbCl}_{3}-\mathrm{PbS} \mathrm{HNCs}$ with different magnification at different locations where the more contrast (black) dot is $\mathrm{PbS}$ and lighter contrast part is $\mathrm{CsPbCl}_{3}$. e) energy dispersive spectroscopy (EDS) analysis showing the elements present in the $\mathrm{CsPbCl}_{3}-\mathrm{PbS}$ HNCs. Inset shows the elemental composition, for clarity elements like $\mathrm{C}, \mathrm{N}$, $\mathrm{Si}$, and $\mathrm{Pt}$ were removed. Morphology of the $\mathrm{CsPbCl}_{3}-\mathrm{PbS}$ HNCs is cubic similar to $\mathrm{CsPbBr}_{3}-$ $\mathrm{PbS}$ HNCs. Small inhomogeneity also there in $\mathrm{CsPbCl}_{3}-\mathrm{PbS}$ HNCs. 


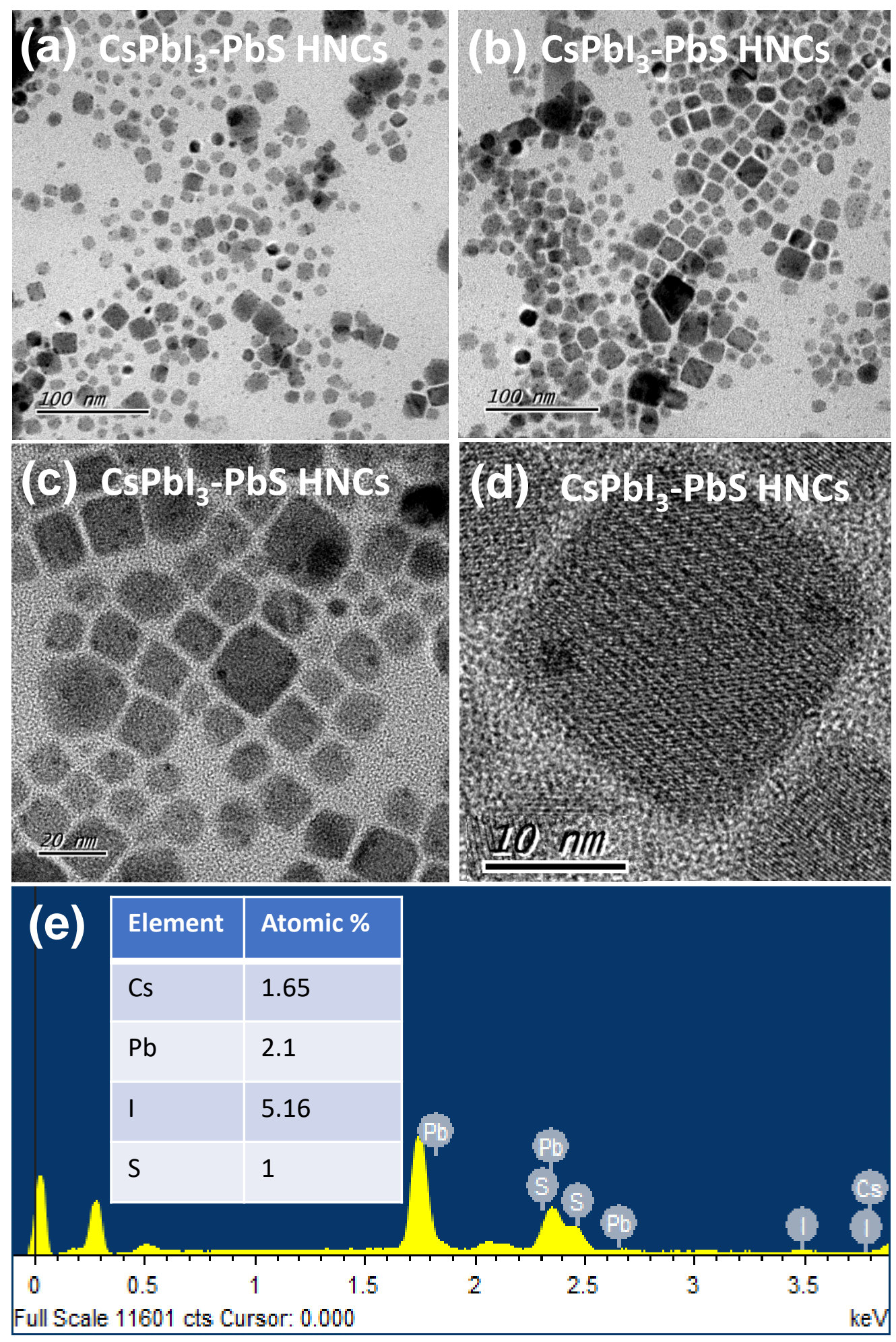

Figure S7. a, b, c d) TEM images of $\mathrm{CsPbI}_{3}-\mathrm{PbS}$ HNCs with different magnification at different locations where the more contrast (black) dot is $\mathrm{PbS}$ and lighter contrast part is $\mathrm{CsPbI}_{3}$. e) EDS analysis showing the elements present in the $\mathrm{CsPbI}_{3}-\mathrm{PbS}$ HNCs. Inset shows the elemental composition, for clarity elements like $\mathrm{C}, \mathrm{N}, \mathrm{Si}$, and $\mathrm{Pt}$ were removed. Morphology of the $\mathrm{CsPbI}_{3}-\mathrm{PbS} \mathrm{HNCs}$ is mostly cubic similar to $\mathrm{CsPbBr}-\mathrm{PbS} \mathrm{HNCs}$. 


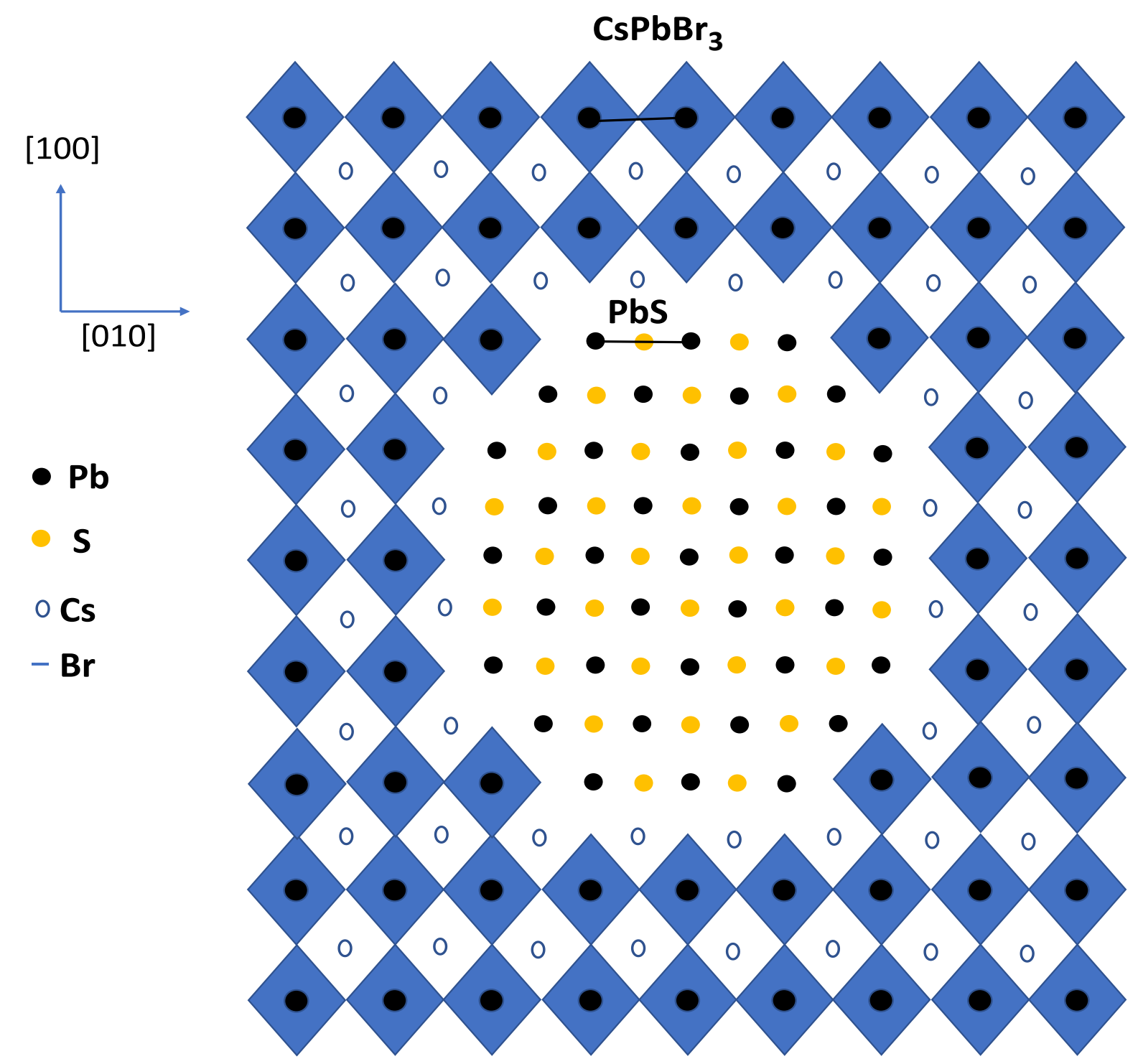

Figure S8. Schematic representation of a $\mathrm{CsPbBr} 3$ perovskite on $\mathrm{PbS}^{4}$ 

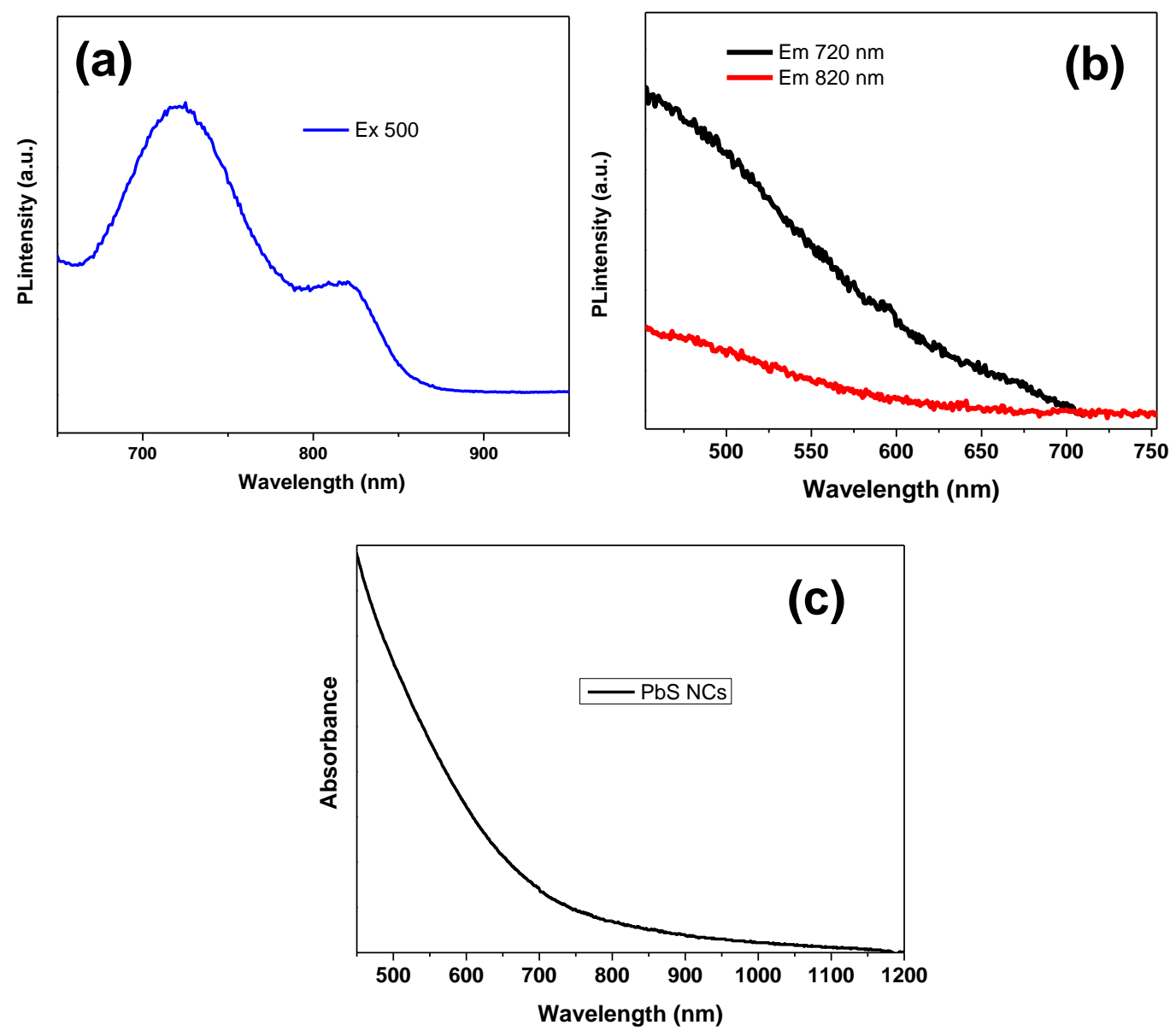

Figure S9. a), b) and c) emission, excitation, and absorption spectra of PbS NCs@ $\mathrm{PbBr}$.
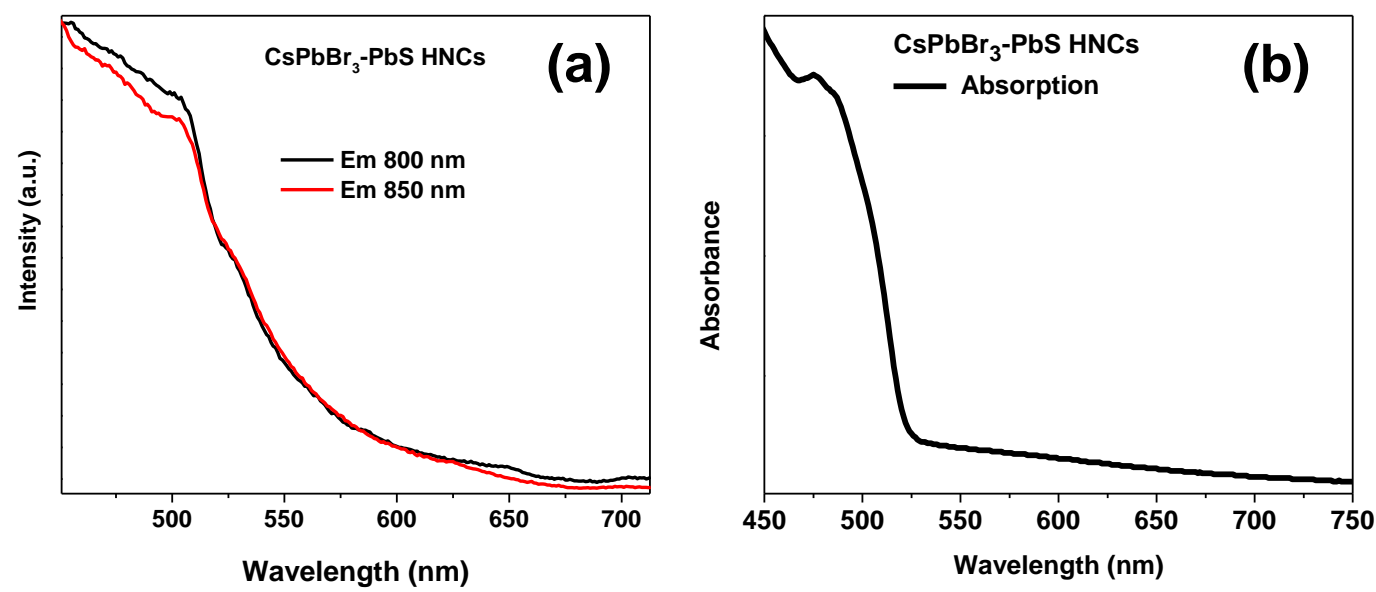

Figure S10. a), b) excitation spectra, and absorption spectra of $\mathrm{CsPbBr}_{3}-\mathrm{PbS} \mathrm{HNCs}$, respectively. 

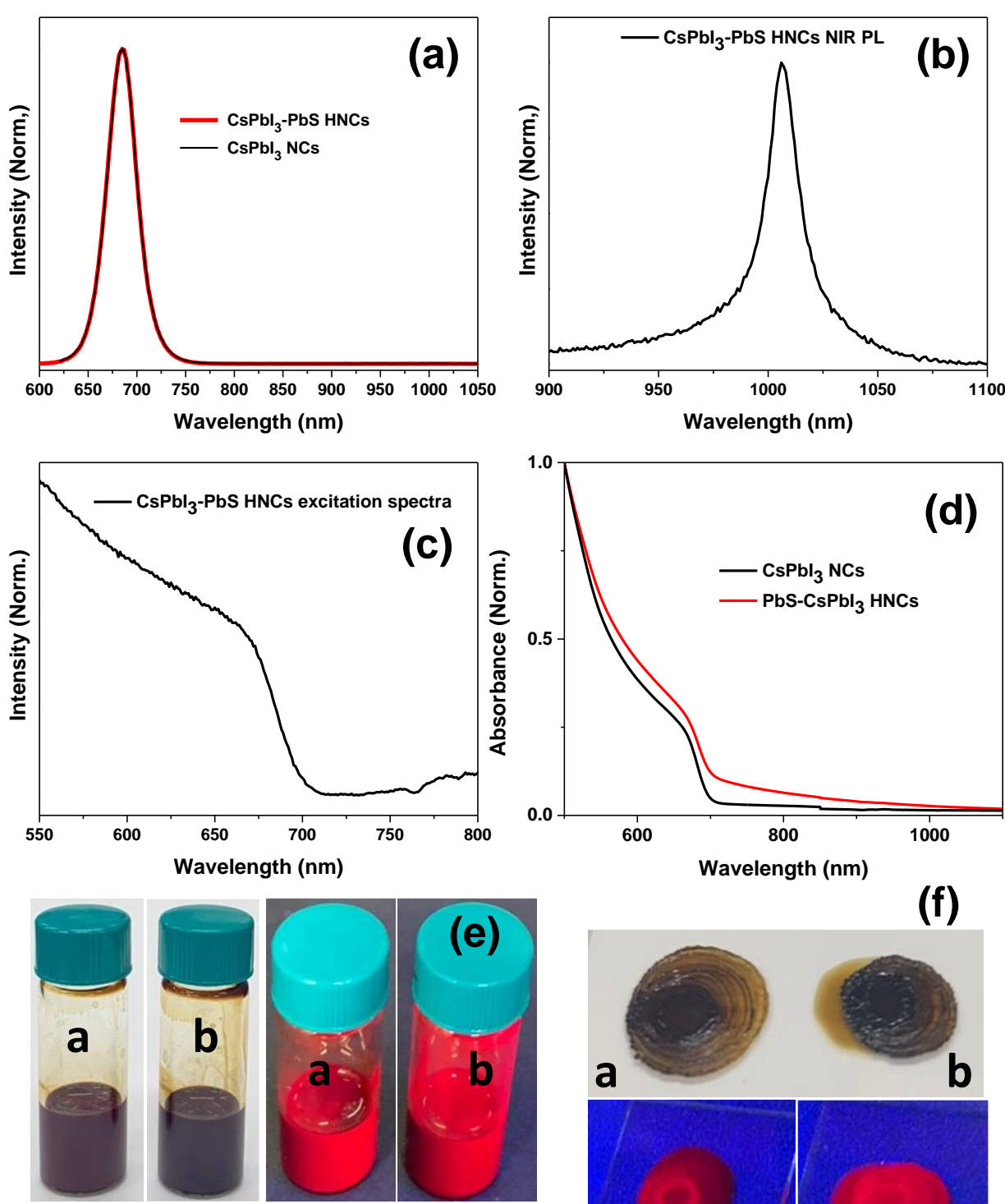

Day light

UV light

a: $\mathrm{CsPbl}_{3} \mathrm{NCs}, \mathrm{b}: \mathrm{PbS}^{-\mathrm{CsPbl}}{ }_{3} \mathrm{HNCs}$

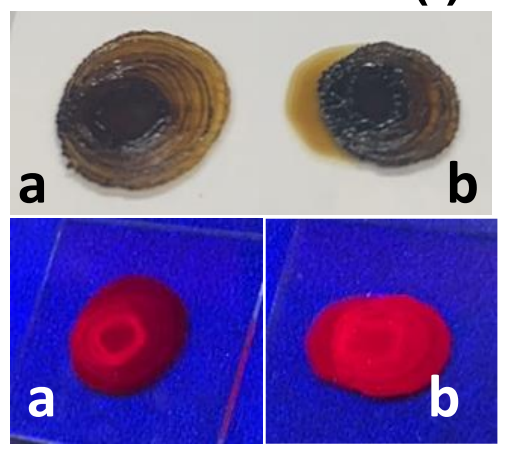

Figure S11. a) PL spectra of $\mathrm{CsPbI}_{3} \mathrm{NCs}_{\text {and }} \mathrm{CsPbI}_{3}-\mathrm{PbS}$ HNCs. b) PL spectrum of $\mathrm{CsPbI}_{3}-$ $\mathrm{PbS}$ HNCs in the NIR region. c) excitation spectrum of $\mathrm{CsPbI}_{3}-\mathrm{PbS} \mathrm{HNCs}$ at $~ 1000 \mathrm{~nm}$. d) absorption spectra of $\mathrm{CsPbI}_{3} \mathrm{NCs}$ and $\mathrm{CsPbI}_{3}-\mathrm{PbS}$ HNCs. NIR PL was also observed for $\mathrm{CsPbI}_{3}-\mathrm{PbS} \mathrm{HNCs}$ at $\sim 1000 \mathrm{~nm}$. The excitation spectrum of $\mathrm{CsPbI}_{3}-\mathrm{PbS} \mathrm{HNCs}$ also agrees with the absorption spectrum of $\mathrm{CsPbI}_{3}-\mathrm{PbS}$ HNCs. However, further investigation is needed to confirm the energy/charge transfer in these HNCs. e,f) Photographs of the solutions and films of $\mathrm{CsPbI}_{3} \mathrm{NCs}$ and $\mathrm{CsPbI}_{3}-\mathrm{PbS} \mathrm{HNCs}$ under Day-light and $365 \mathrm{~nm}$ light irradiation. PLQYs of the solutions of $\mathrm{CsPbI}_{3} \mathrm{NCs}$ and $\mathrm{CsPbI}_{3}-\mathrm{PbS}$ HNCs are found to be $45 \pm 5$ and $60 \pm 4$. 

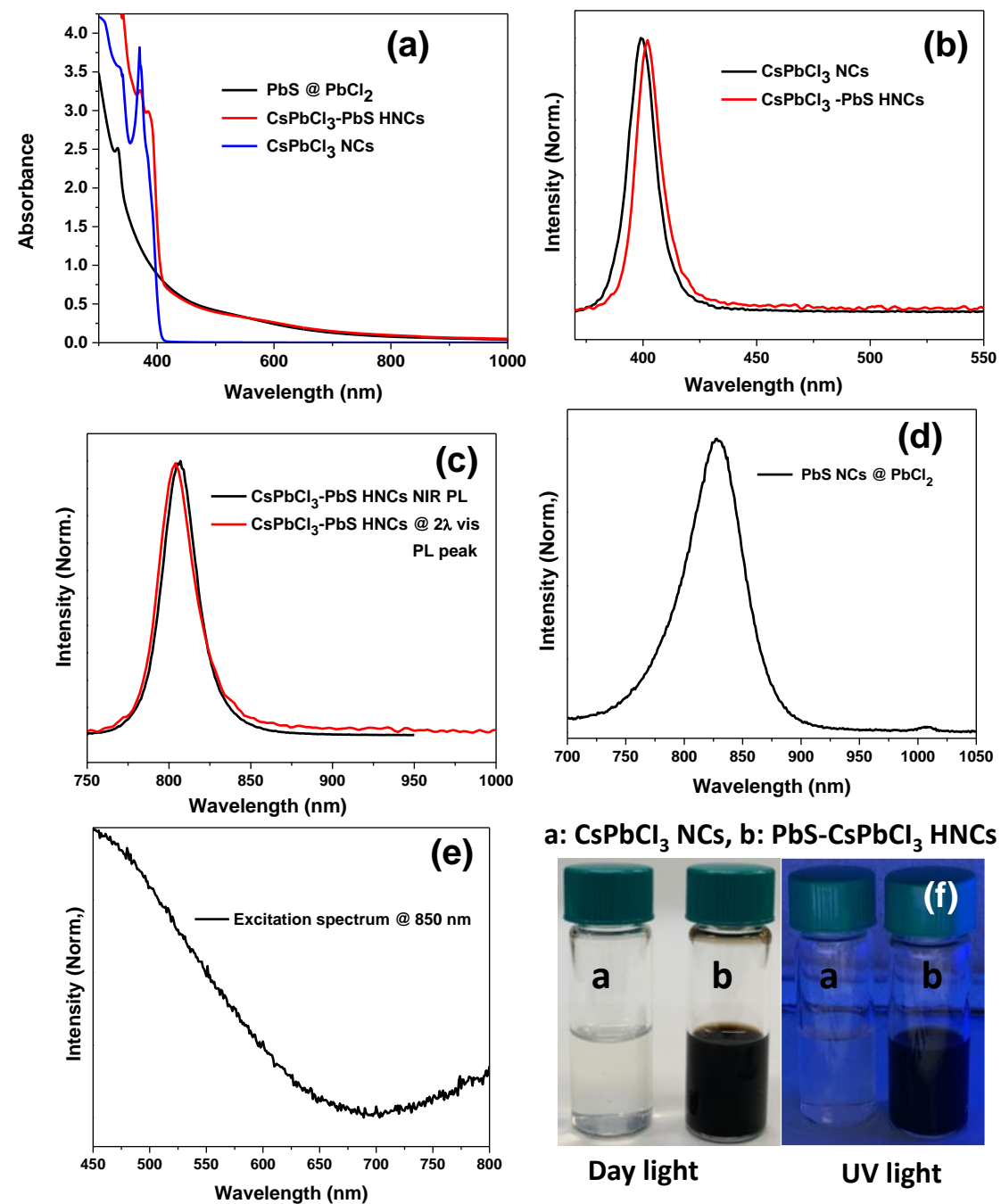

Figure S12. a) absorption spectra of $\mathrm{CsPCl}_{3} \mathrm{NCs}, \mathrm{PbS}$ NCs and $\mathrm{CsPbCl}_{3}-\mathrm{PbS} \mathrm{HNCs}$. b and c) photoluminescence (PL) spectrum of $\mathrm{CsPbCl}_{3}$ and $\mathrm{CsPbCl}_{3}-\mathrm{PbS}$ HNCs in the visible region, NIR region respectively. d) PL spectrum and e) excitation spectrum of $\mathrm{PbS}$ NCs (prepared from $\mathrm{PbCl}_{2}$ ). We note that it is difficult to distinguish the NIR PL of $\mathrm{CsPbCl}_{3}-\mathrm{PbS} \mathrm{HNCs}$ due to the overlap of $2 \lambda$ peak i.e. $2 x \mathrm{PL}$ peak in the visible region of $\mathrm{CsPbCl}_{3}-\mathrm{PbS}$ HNCs. Since we are not sure of NIR PL, therefore we did not study the electronic band alignment studies using UPS. f) Photographs of the solutions of $\mathrm{CsPbCl}_{3} \mathrm{NCs}_{\text {and }} \mathrm{CsPbCl}_{3}-\mathrm{PbS}$ HNCs under Day-light and $365 \mathrm{~nm}$ light irradiation. The PLQYs of the solutions of $\mathrm{CsPbCl}_{3} \mathrm{NCs}$ and $\mathrm{CsPbCl}_{3}-\mathrm{PbS}$ HNCs are found to be $3 \pm 1$ and $5 \pm 2$. 

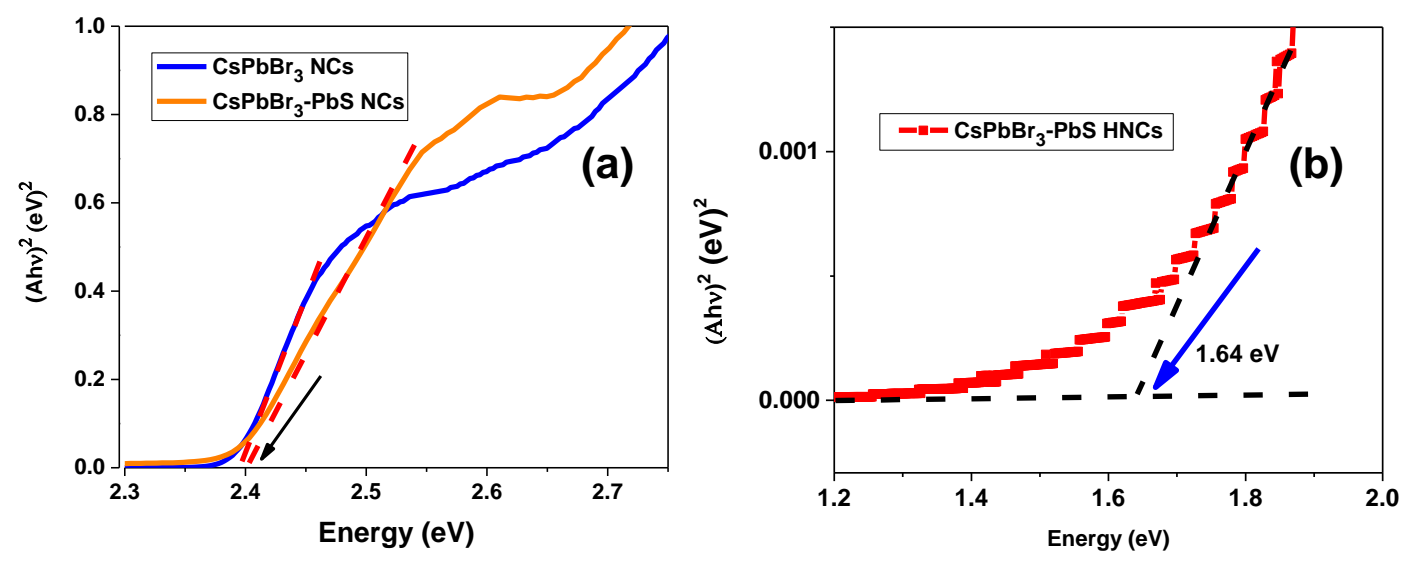

Figure S13. $(\mathrm{Ah} v)^{2}$ vs energy plot for a) $\mathrm{CsPbBr}_{3}-\mathrm{PbS} \mathrm{HNCs}$ and $\mathrm{CsPbBr}_{3} \mathrm{NCs}$ in the visible region, b) $\mathrm{Cs} \mathrm{PbBr}_{3}-\mathrm{PbS} \mathrm{HNCs}$ in the near-infrared region.
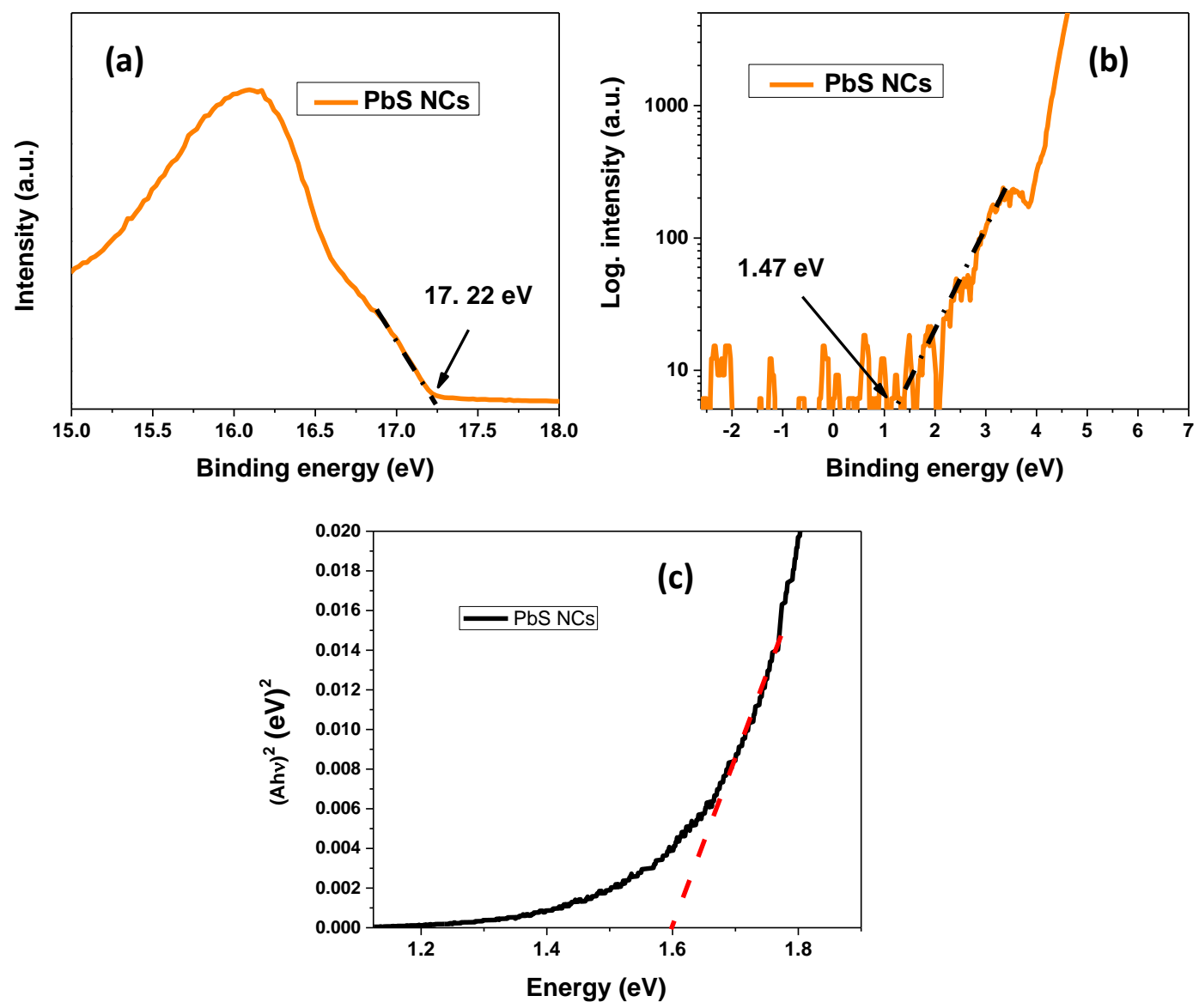

Figure S14. a), b) Ultraviolet photoelectron spectroscopy (UPS) performed for PbS NCs ((prepared from $\mathrm{PbBr}_{2}$ as lead source and thioacetamide being a sulfur source) in the cut-off region and valence region, respectively. c) $(\mathrm{Ah} v)^{2}$ vs energy plot for $\mathrm{PbS} \mathrm{NCs}$ in the NIR region. . 


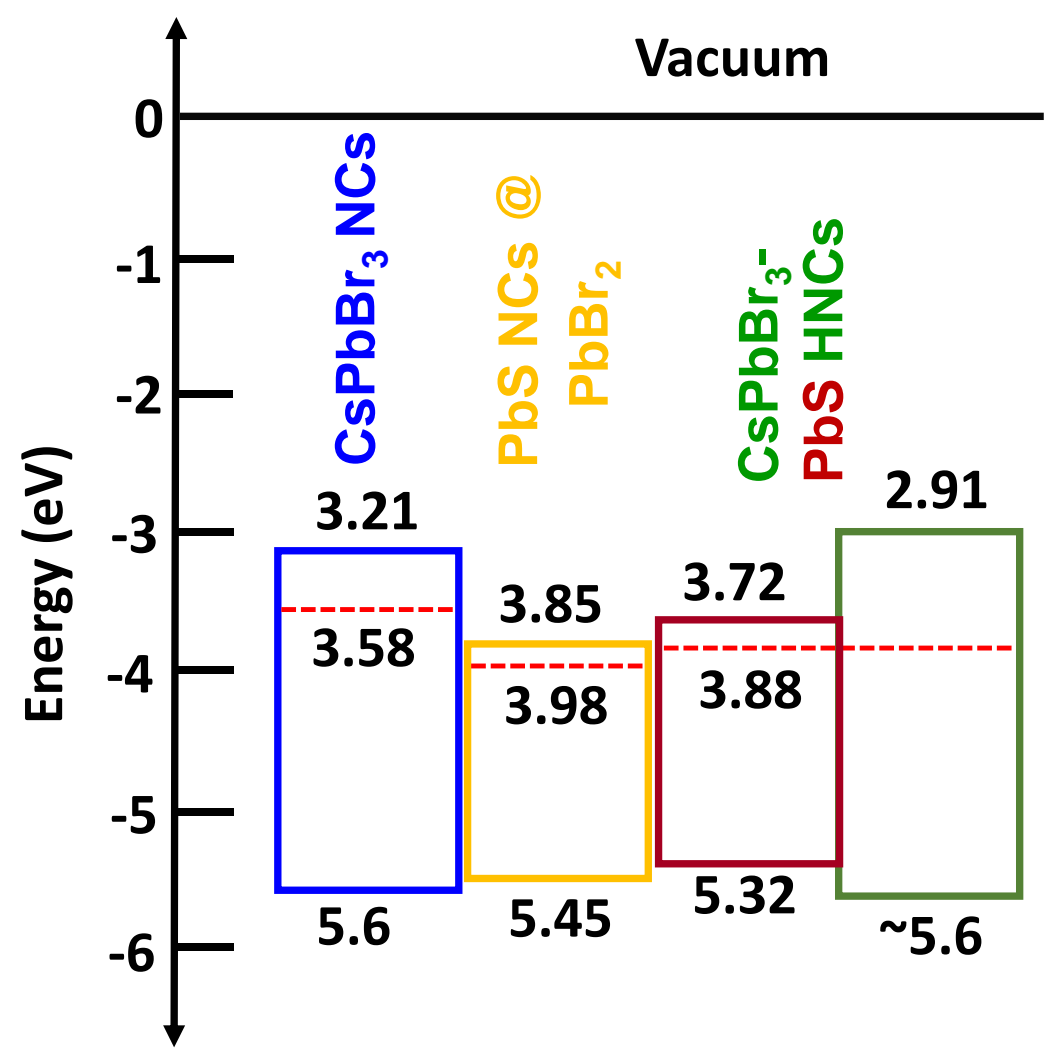

Figure S15. Valence band maximum (VBM), conduction band minimum (CBM), and Fermi energy levels have been extracted from UPS and absorption spectra for $\mathrm{CsPbBr}_{3} \mathrm{NCs}, \mathrm{PbS}$ $\mathrm{NCs}$, and $\mathrm{CsPbBr}_{3}-\mathrm{PbS}$ HNCs, respectively. The small changes in the VBM and CBM level of $\mathrm{PbS}$ and $\mathrm{CsPbBr}_{3}$ for $\mathrm{HNCs}$ compared with the as-prepared samples can be attributed to the different chemical environments and size inhomogeneity. Further, it is evident from the Fourier Transform Infrared Spectroscopy (FTIR) analysis.

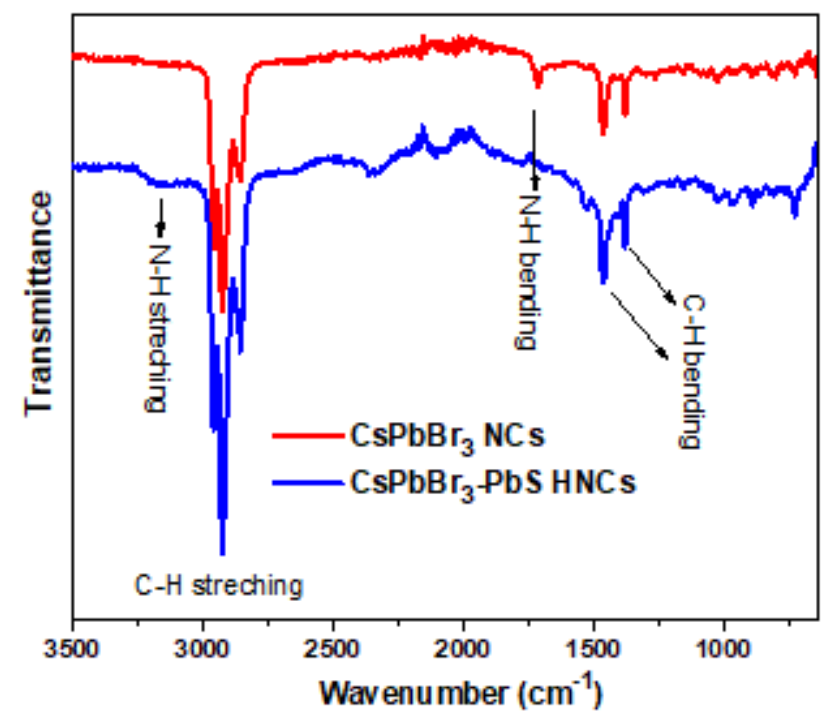

Figure S16. FTIR spectrum of $\mathrm{CsPbBr}_{3} \mathrm{NCs}$ and $\mathrm{CsPbBr}_{3}-\mathrm{PbS}$ HNCs. FTIR spectrum does not show any detectable contribution from $\mathrm{C}=\mathrm{S}$ bond (thioacetamide) on the surface for $\mathrm{CsPbBr} 3-\mathrm{PbS}$ HNCs. 

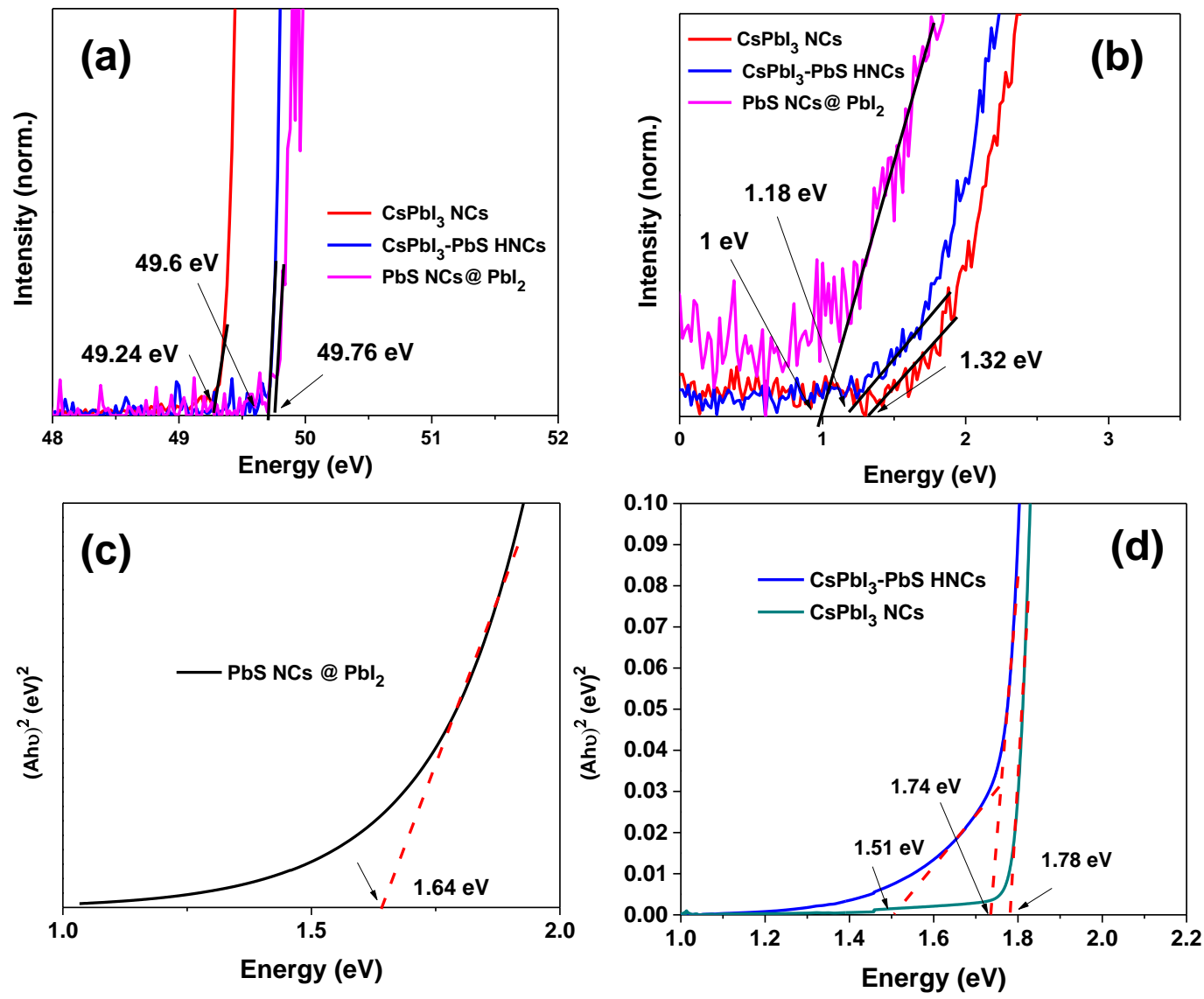

Figure S17. a, b) UPS performed for PbS NCs (prepared from $\mathrm{PbI}_{2}$ as lead source and thioacetamide being a sulfur source) in the cut-off region and valence region, respectively. c,d) $(\mathrm{Ahv})^{2}$ vs energy plot for $\mathrm{PbS} \mathrm{NCs}, \mathrm{CsPbI}_{3} \mathrm{NCs}$, and $\mathrm{CsPbI}_{3} \mathrm{PbS}$ HNCs respectively, in the NIR region. 


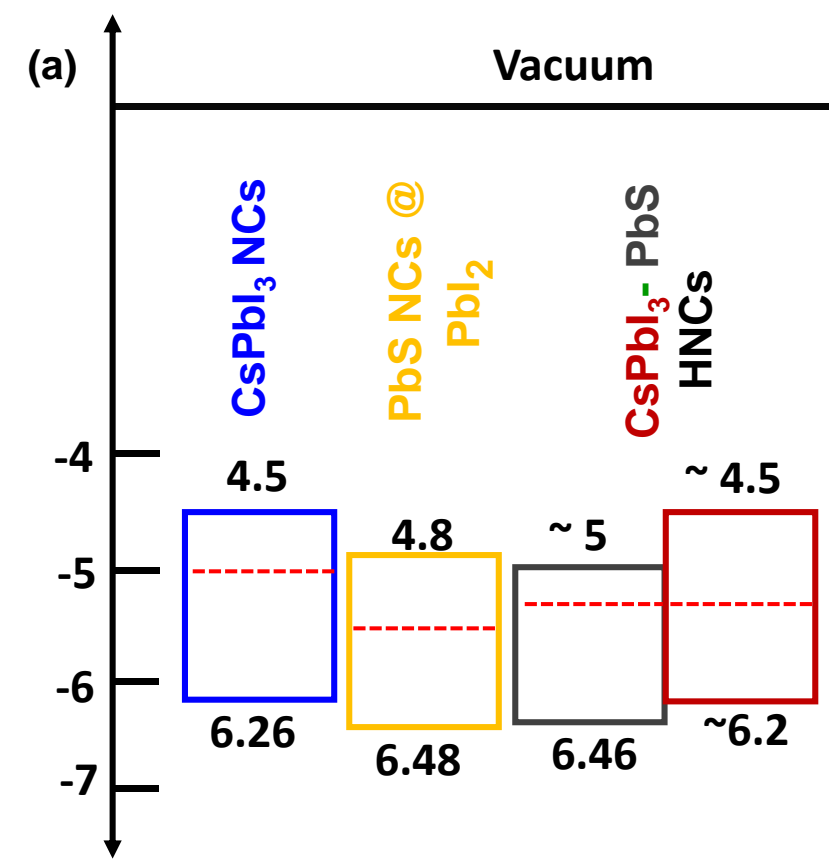

(b) Type-II band alignment
of $\mathrm{CsPbl}_{3}-\mathrm{PbS}$ HNCs

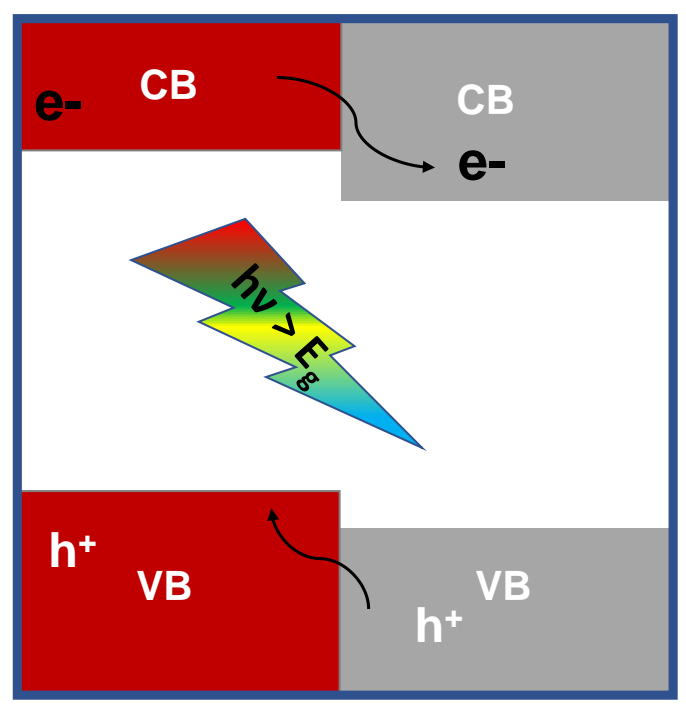

Figure S18. a) Valence band maximum (VBM), conduction band minimum (CBM), and Fermi levels have been extracted from UPS and absorption spectra for $\mathrm{CsPI}_{3} \mathrm{NCs}, \mathrm{PbS} \mathrm{NCs}$, and $\mathrm{CsPbI}_{3}-\mathrm{PbS} \mathrm{HNCs}$, respectively. b) Schematic representation of type-II band alignment of $\mathrm{CsPbI}_{3}-\mathrm{PbS}$ HNCs obtained from UPS and absorption spectroscopy. Type-II band alignment allows electron-hole charge separation across the interface upon illumination of light.
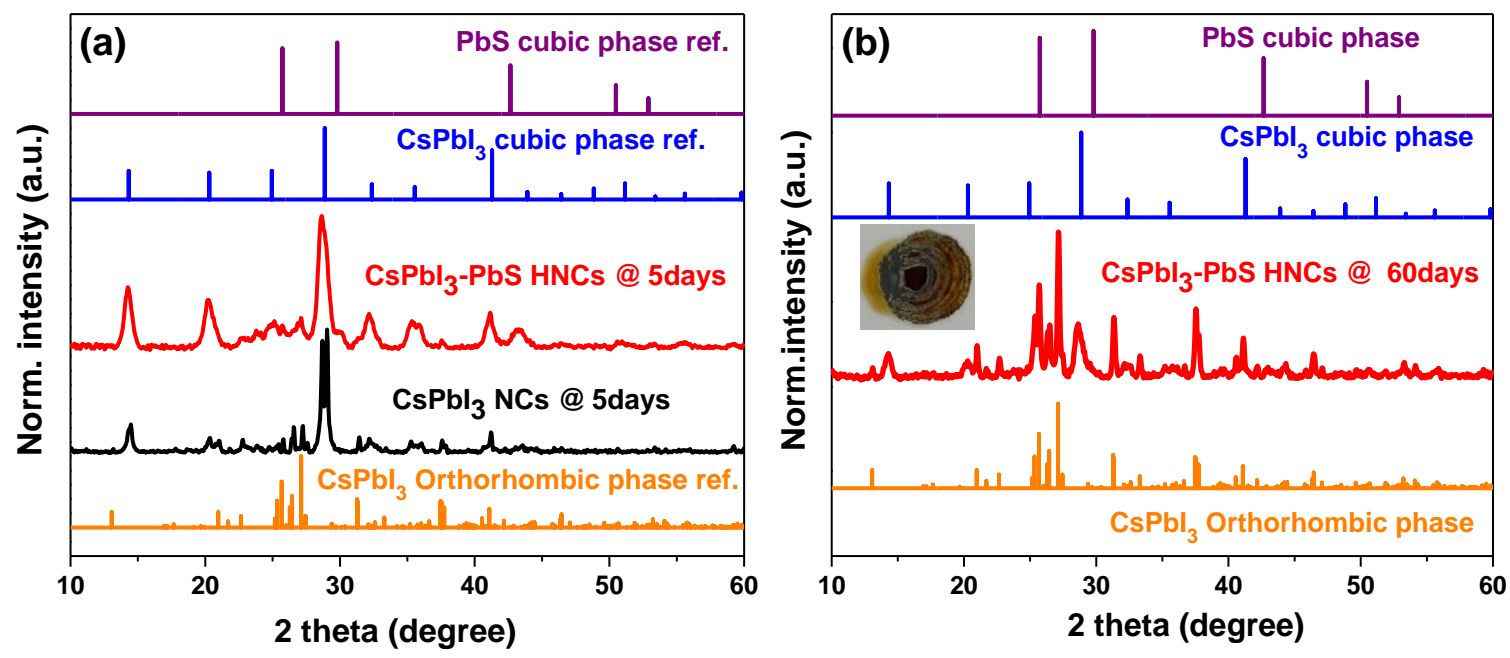

Figure S19. a) and b) XRD patterns of the films of $\mathrm{CsPbI}_{3} \mathrm{NCs}$ and $\mathrm{CsPbI}_{3}-\mathrm{PbS} \mathrm{HNCs}$ on $5^{\text {th }}$ and $60^{\text {th }}$ day after making. Reference patterns of $\mathrm{CsPbI}_{3}$ and $\mathrm{PbS}$ are also provided. In the period of 60 days film of $\mathrm{CsPbI}_{3}-\mathrm{PbS} \mathrm{HNCs}$ showing the co-existence of cubic and orthorhombic XRD peaks. Inset in $b$ ) shows the brown color of the film of $\mathrm{CsPbI}_{3}-\mathrm{PbS} \mathrm{HNCs}$ and it will take more days to complete conversion from cubic to orthorhombic phase. 

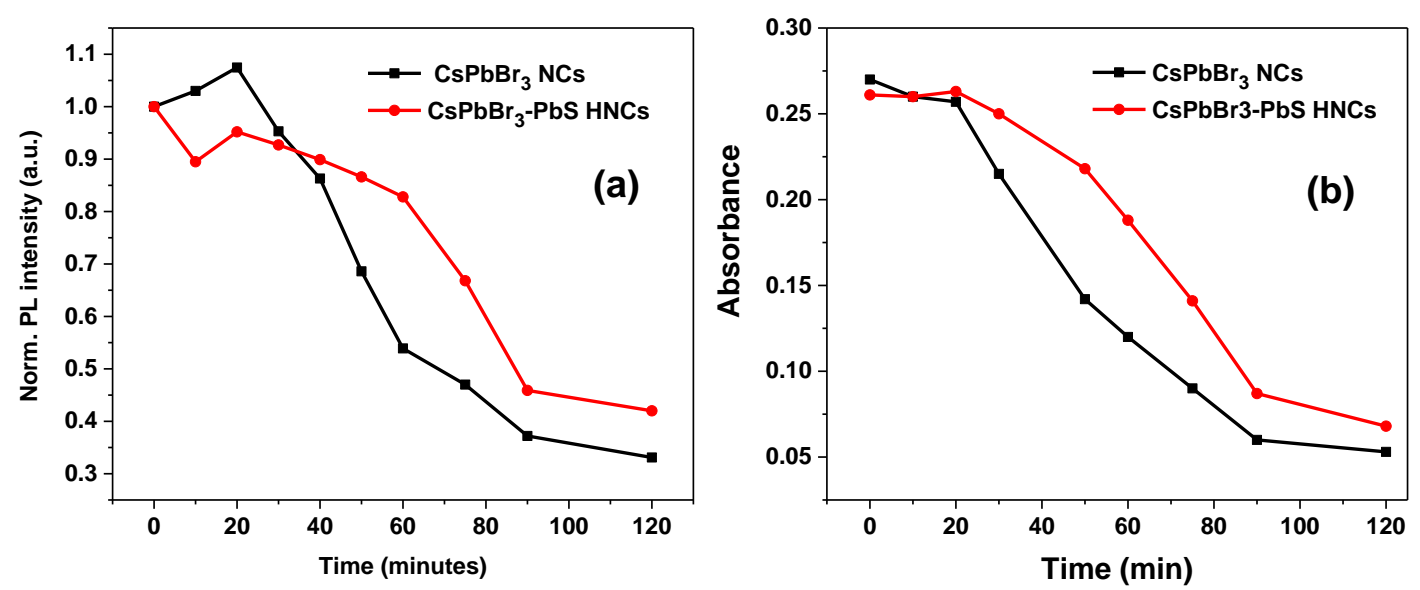

Figure S20. We wanted to show the effect of polar solvents on these NCs because often NCs experience such polar environments in making optoelectronic devices and photocatalytic reactions. i.e., Coating of NCs on top of PEDOT, $\mathrm{ZnO}, \mathrm{TiO}_{2}, \mathrm{SnO}_{2}$, etc layers which are often dispersed in polar solvents. Therefore, we did a simple experiment by adding a small amount of ethanol to the dispersions of NCs, and their UV and PL were checked over time to check the stability of our HNCs. To check the stability, $50 \mu \mathrm{L}$ of ethanol was added to $3 \mathrm{~mL} \mathrm{NCs}$ dispersion with similar concentration. a) the change in PL intensity, b) the change in the absorbance for $\mathrm{CsPbBr}_{3} \mathrm{NCs}$ and $\mathrm{CsPbBr}_{3}-\mathrm{PbS}$ HNCs over a period of 120 minutes.

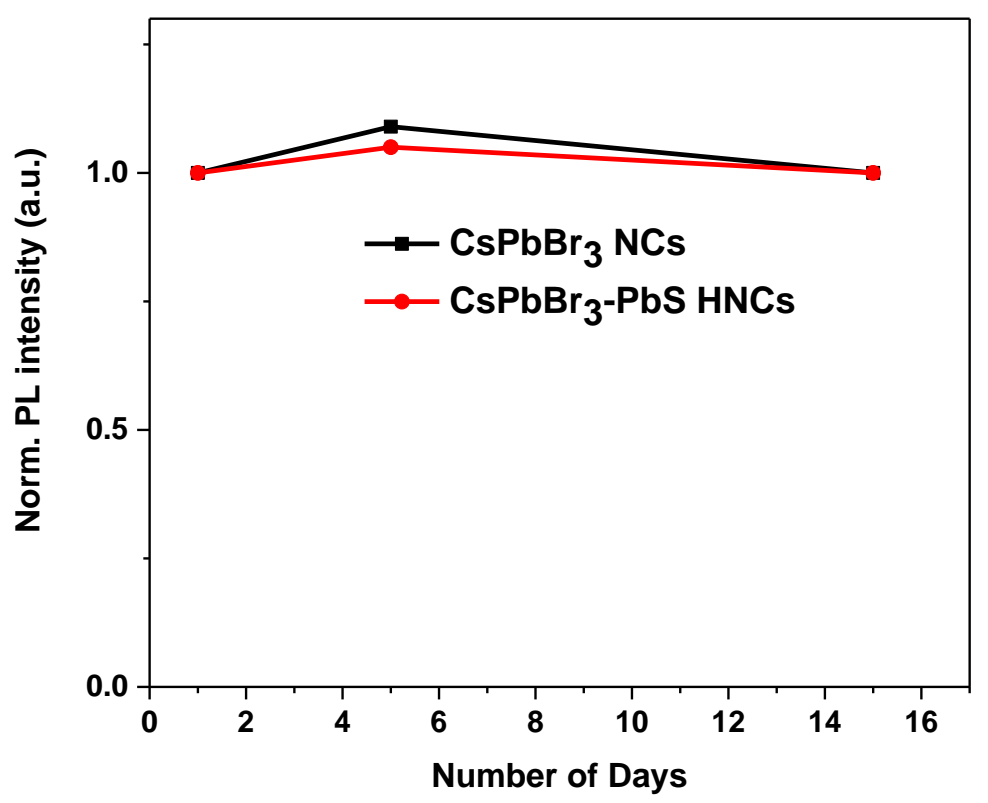

Figure S21. Change in PL intensity of films of $\mathrm{CsPbBr}_{3} \mathrm{NCs}$ and $\mathrm{CsPbBr}_{3}-\mathrm{PbS}$ HNCs under ambient conditions. The PL QY of $\mathrm{CsPbBr}_{3} \mathrm{NCs}$ is less than that of HNCs. This indicates that $\mathrm{CsPbBr}_{3} \mathrm{NCs}$ contain more defects than HNCs. It has been shown in the literature that oxygen passivates defects of perovskite films in the ambient air. This defect passivation has been studied in solar cell applications. ${ }^{5,6}$ Probably, in our case also, $\mathrm{CsPbBr}_{3} \mathrm{NCs}$ containing more defects might be passivated by oxygen. However, further investigation is needed to verify this. 

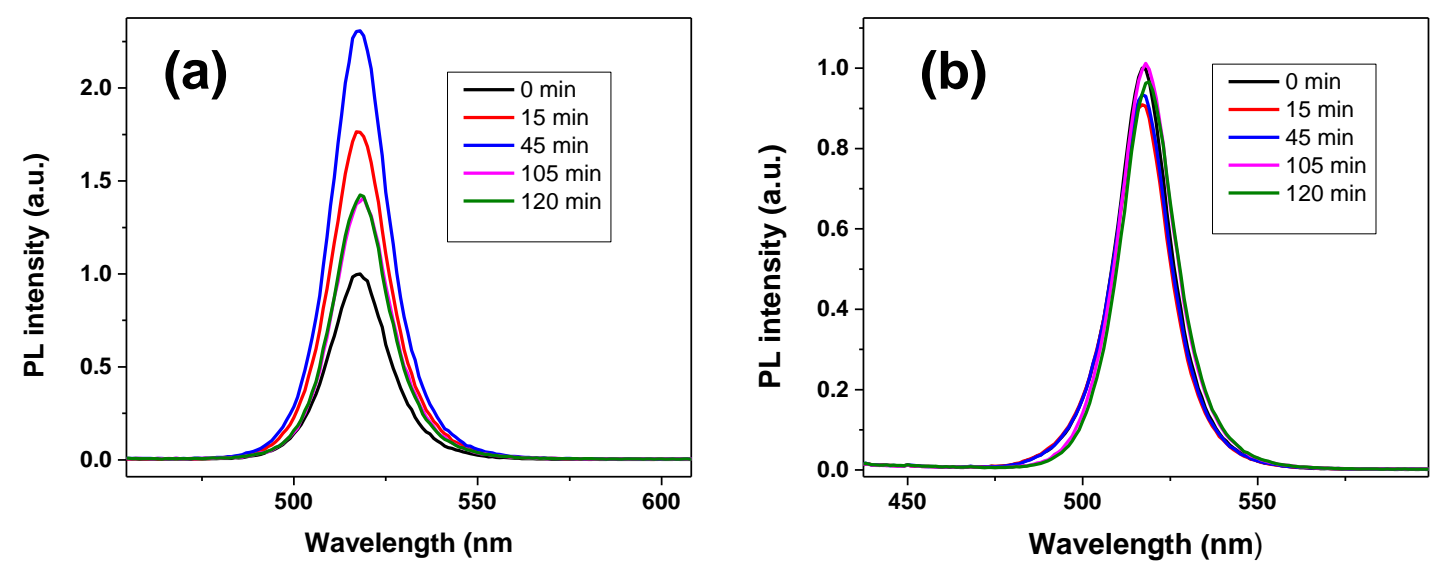

Figure S22. Change in $\mathrm{PL}$ intensity of films of $\mathrm{CsPbBr}_{3} \mathrm{NCs}$ and $\mathrm{CsPbBr}_{3}-\mathrm{PbS} \mathrm{HNCs}$ under continuous $365 \mathrm{~nm}$ UV light source for 2 hours. 

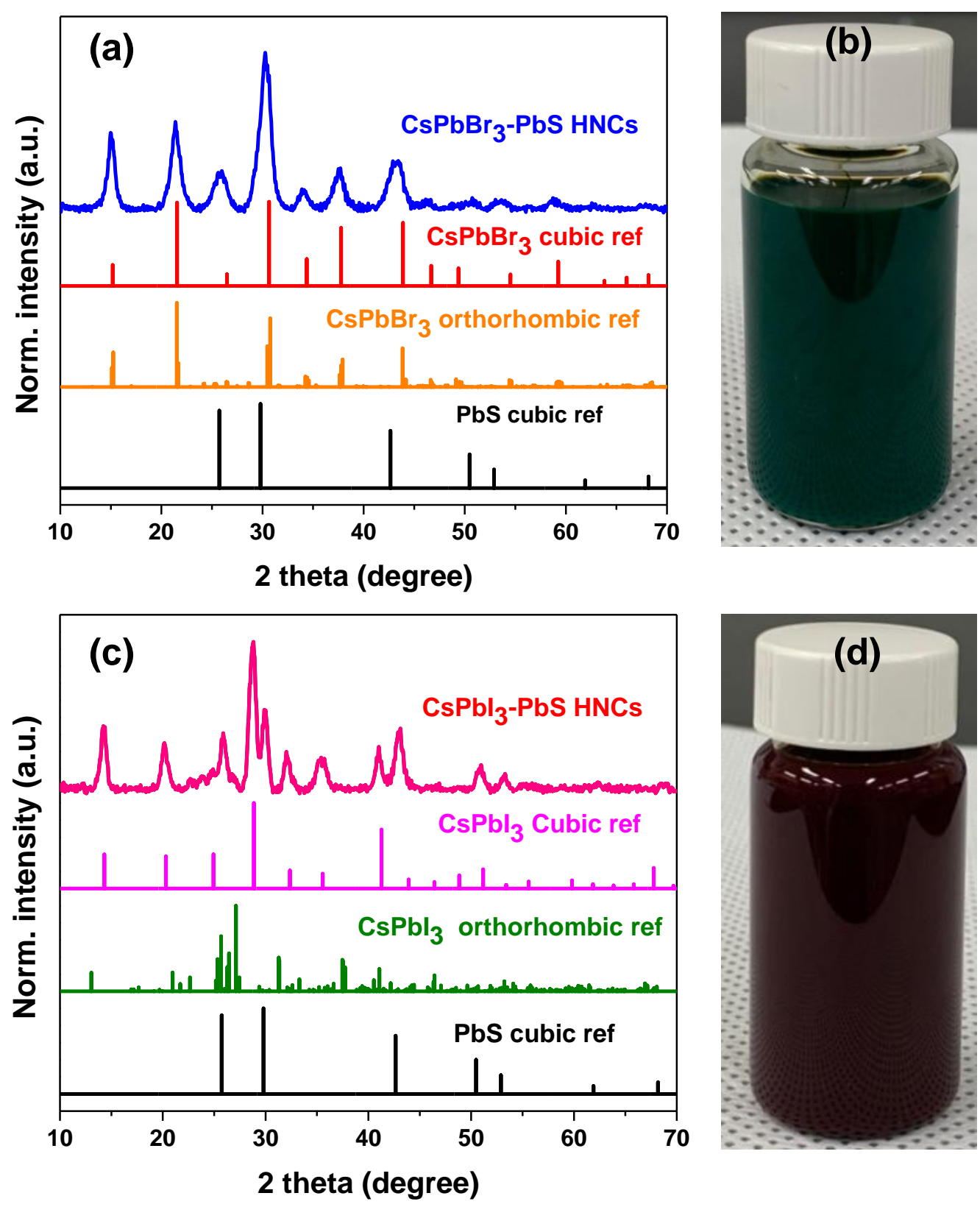

Figure S23. a, c) XRD patterns and b, d) photograph of the large-scale synthesis of $\mathrm{CsPbBr}_{3}$ $\mathrm{PbS}$ HNCs and $\mathrm{CsPbI}_{3}-\mathrm{PbS} \mathrm{HNCs}$, respectively. 
Table S1: The ${ }^{207} \mathrm{~Pb}$ NMR parameters of the nanocrystal samples determined via Gaussian/Lorentzian fitting (except for $\mathrm{CsPbBr}_{3}$ which was simulated with a $J$-coupling multiplet with ${ }^{1} J\left({ }^{207} \mathrm{~Pb}-{ }^{79 / 81} \mathrm{Br}\right)=2.3 \pm 0.3 \mathrm{KHz}$ and individual spikelet $\mathrm{FWHM}=2.64 \pm 0.3$ $\mathrm{kHz})$.

\begin{tabular}{|c|c|c|c|c|}
\hline Nanocrystals & Assignment & $\begin{array}{c}\boldsymbol{\delta}_{\text {iso }}\left({ }^{\mathbf{2 0 7}} \mathbf{P b}\right) \\
(\mathrm{ppm})\end{array}$ & $\begin{array}{c}\text { FWHM } \\
(\mathrm{KHz})\end{array}$ & $\begin{array}{c}\text { Relative } \\
\text { intensity } \\
(\%)\end{array}$ \\
\hline $\mathrm{CsPbr}_{3}$ & - & $260 \pm 1$ & - & - \\
\hline $\mathrm{PbS}$ & - & $1380 \pm 30$ & $63 \pm 8$ & - \\
\hline $\mathrm{CsPbBr}_{3}-\mathrm{PbS}$ & $\mathrm{CsPbBr} 3$ & $240 \pm 10$ & $22 \pm 3$ & 74.2 \\
& $\mathrm{PbS}$ & $1270 \pm 50$ & $110 \pm 10$ & 25.8 \\
\hline
\end{tabular}

Table S2: The ${ }^{133}$ Cs NMR parameters of the nanocrystal samples determined via Gaussian/Lorentzian fitting

\begin{tabular}{|c|c|c|c|c|}
\hline Nanocrystals & Assignment & $\begin{array}{c}\boldsymbol{\delta}_{\text {iso }}\left({ }^{\mathbf{1 3 3}} \mathbf{C s}\right) \\
(\mathrm{ppm})\end{array}$ & $\begin{array}{c}\text { FWHM } \\
(\mathrm{kHz})\end{array}$ & $\begin{array}{c}\text { Relative } \\
\text { intensity } \\
(\%)\end{array}$ \\
\hline $\mathrm{CsPBr}_{3}$ & Bulk & $120.0 \pm 0.2$ & $0.29 \pm 0.04$ & 36.6 \\
& Near-surface layers & $116.7 \pm 0.6$ & $0.73 \pm 0.09$ & 24.9 \\
& & $105 \pm 2$ & $2.1 \pm 0.3$ & 38.5 \\
\hline $\mathrm{CsPbBr} 3-\mathrm{PbS}$ & CsPbBr3 & $116 \pm 1$ & $0.75 \pm 0.09$ & 3.3 \\
& Distorted CsPbBr3 & $101 \pm 2$ & $2.1 \pm 0.2$ & 88.8 \\
& Boundary sites & $193 \pm 2$ & $2.4 \pm 0.3$ & 5.3 \\
& & $170.1 \pm 1$ & $1.6 \pm 0.2$ & 2.6 \\
\hline
\end{tabular}




\section{REFERENCES}

(1). Hu, L.; Zhao, Q.; Huang, S.; Zheng, J.; Guan, X.; Patterson, R.; Kim, J.; Shi, L.; Lin, C.-H.; Lei, Q.; Chu, D.; Tao, W.; Cheong, S.; Tilley, R. D.; Ho-Baillie, A. W. Y.; Luther, J. M.; Yuan, J.; Wu, T., Flexible and Efficient Perovskite Quantum Dot Solar Cells via Hybrid Interfacial Architecture. Nat. Commun. 2021, 12, 466.

(2). Massiot, D.; Fayon, F.; Capron, M.; King, I.; Le Calvé, S.; Alonso, B.; Durand, J.-O.; Bujoli, B.; Gan, Z.; Hoatson, G., Modelling One- and Two-Dimensional Solid-State NMR Spectra. Magn. Reson. Chem. 2002, 40, 70-76.

(3). La Mer V.K.; Dinegar R.H. Theory, Production and Mechanism of Formation of Monodispersed Hydrosols. J. Am. Chem. Soc. 1950, 72, 4847.

(4). Liu, M.; Chen, Y.; Tan, C.-S.; Quintero-Bermudez, R.; Proppe, A. H.; Munir, R.; Tan, H.; Voznyy, O.; Scheffel, B.; Walters, G.; Kam, A. P. T.; Sun, B.; Choi, M.-J.; Hoogland, S.; Amassian, A.; Kelley, S. O.; García de Arquer, F. P.; Sargent, E. H., Lattice Anchoring Stabilizes SolutionProcessed Semiconductors. Nature 2019, 570, 96-101.

(5). Huang, L.; Ge, Z.; Zhang, X.; Zhu, Y., Oxygen-Induced Defect-Healing and Photo-Brightening of Halide Perovskite Semiconductors: Science and Application. J. Mater. Chem. A 2021, 9, 4379-4414.

(6). Liu, S.-C.; Li, Z.; Yang, Y.; Wang, X.; Chen, Y.-X.; Xue, D.-J.; Hu, J.-S., Investigation of Oxygen Passivation for High-Performance All-Inorganic Perovskite Solar Cells. J. Am. Chem. Soc. 2019, 141, 18075-18082. 